\title{
The clinical relevance of the Hippo pathway in pancreatic ductal adenocarcinoma
}

\author{
Richard Drexler ${ }^{1,2} \oplus \cdot$ Mirco Küchler $^{1,2} \cdot$ Kim C. Wagner $^{1,2} \cdot$ Tim Reese $^{1,2} \cdot$ Bernd Feyerabend $^{3} \cdot$ Moritz Kleine $^{4}$. \\ Karl J. Oldhafer ${ }^{1,2}$
}

Received: 23 September 2020 / Accepted: 10 October 2020 / Published online: 24 October 2020

(c) The Author(s) 2020

\begin{abstract}
Purpose The Hippo pathway has broadened in cancer research in the past decade and revealed itself to be an important driver for tumorigenesis and metastatic spread. In this study, we investigated the clinical relevance of the Hippo pathway with regard to metastatic invasion, patients' outcome and histopathological features.

Methods Protein expression of components of the Hippo pathway were analyzed by immunohistochemistry (IHC) using paraffin-embedded tissue from 103 patients who had been diagnosed with pancreatic ductal adenocarcinoma and had undergone surgery. Results were correlated with clinicopathological data, disease-free and overall survival.

Results Immunohistochemistry studies in pancreatic tumour tissues revealed a significant upregulation of MST1, MST2, pLATS, pYAP and 14-3-3, representing the active Hippo pathway, in non-metastasized patients $(p<0.01)$. In turn, the pathway is more inactive in metastasized patients and relating liver metastases as LATS1, LATS2, YAP, transcriptional factors TEAD2 and TEAD3 were upregulated in these patients $(p<0.01)$. A higher pYAP expression was associated with a favorable OS and DFS.

Conclusion The Hippo pathway is inactive in metastasized patients releasing the pro-metastatic and proliferative potential of the pathway. Furthermore, our study underlines the prognostic relevance of the Hippo pathway as a shift in the balance towards the inactive pathway predicts an unfavorable OS and DFS.
\end{abstract}

Keywords Hippo pathway $\cdot$ Pancreatic cancer $\cdot$ Metastasis $\cdot$ PDAC $\cdot$ Prognosis

\section{Introduction}

Pancreatic ductal adenocarcinoma (PDAC) remains a challenging disease with a poor prognosis. The 5-year survival rate is between 4 and $8 \%$ with surgical resection remaining the only curative option (Ilic and Ilic 2016; Ferlay et al. 2013). At the time of diagnosis only $15-20 \%$ of patients

Richard Drexler

richard.drexler@semmelweis-hamburg.de

$\triangle$ Karl J. Oldhafer

k.oldhafer@asklepios.com

1 Asklepios Campus Hamburg, Semmelweis University Budapest, Hamburg, Germany

2 Division of HPB Surgery, Department of Surgery, Asklepios Hospital Barmbek, Hamburg, Germany

3 MVZ Hanse Histologikum GmbH, Hamburg, Germany

4 Department of General, Visceral and Transplant Surgery, Hannover Medical School, Hannover, Germany are eligible for surgery and up to $50 \%$ of patients display hepatic metastasis (Siegel et al. 2018; Vincent et al. 2011). Ultimately $70 \%$ of the patients die from metastatic disease (Hogendorf et al. 2018; Ryan et al. 2014a, b).

The Hippo pathway consists of a large network of proteins, which control end organ size of different tissues, by regulating proliferation, cell growth, and apoptosis (Yu et al. 2015; Zhao et al. 2007; Saucedo and Edgar 2007). The pathway comprises of a core kinase cascade, starting with an activation of a pair of serine/threonine kinases mammalian STE20-like protein kinase (MST1/2), which activate another set of kinases, pair large tumour suppressor kinase (LATS). LATS $1 / 2$ phosphorylates the transcriptional activator Yesassociated protein (YAP), causing it to be transported from the nucleus to the cytoplasm. As a result, phosphorylated YAP (pYAP) accumulates with 14-3-3 protein, which causes cytoplasmatic sequestration (Boggiano et al. 2011; Poon et al. 2011; Glantschnig et al. 2002; Hergovich et al. 2006; Meng et al. 2015; Chan et al. 2005, p. 20). When the 
pathway is inactive, YAP can be found in the nucleus and interacts with transcription factors there, like TEAD 1-4 (Holden and Cunningham 2018; Lin et al. 2017a, b). The localization and phosphorylation of YAP are often used as a measure of Hippo pathway activity. Several studies prove that an overexpression of YAP is active in human cancer and successfully demonstrate that a higher expression or activity of YAP is linked with worse patient prognoses in various tumour entities (Wu et al. 2017; Poma et al. 2018; Yu et al. 2015; Harvey et al. 2013; Liu et al. 2018a, b; Zhang et al. 2015a, b; Zanconato et al. 2016). Furthermore, there is evidence that YAP is sufficient to drive cancer metastasis (Lamar et al. 2012; Nallet-Staub et al. 2014; Lau et al. 2014; Gu et al. 2016; Li et al. 2017, p. 1; Kim et al. 2017; Liu et al. 2016, p. 4, 2018a, b; Diepenbruck et al. 2014; Wang et al. 2018; Han et al. 2017, p. 16; Qiao et al. 2017; Zhou et al. 2016). In PDAC, the Hippo pathway has a pivotal role in disease progression, with formation of metastasis and YAP overexpression, which both correlate with an unfavorable OS (Xie et al. 2015; Salcedo Allende et al. 2017; Chen et al. 2015; Zhang et al. 2014). Here, we present the expression of all major proteins of the Hippo pathway in the largest trial population to date. The immunohistochemical results are linked with clinicopathological data including OS and DFS, which demonstrates the clinical impact of the pathway on patients with PDAC.

\section{Materials and methods}

\section{Ethics approval}

All patients' data were fully anonymized, and the study was performed according to the standards set in the Declaration of Helsinki 1975. The tumour tissue used was remaining from material that initially had been collected for diagnostic purposes. All diagnostic procedures had already been fully completed when the samples were retrieved for the study. The study was approved by the Ethics Committee Hamburg, Germany (approval number PV5510).

\section{Patients' characteristics}

A total of 103 patients (female, $n=51$; male, $n=52$; median age, 67.8 years) diagnosed with PDAC, all of whom had undergone surgery between 2010 and 2018 at the Department of Surgery, Asklepios Hospital Barmbek-Hamburg (Germany) were included. The diagnosis was histologically confirmed and TNM classification was assessed according to the AJCC 7th edition. The R-status was obtained pathologically via the circumferential resection margin. All patients had a follow-up either up to their death $(n=76)$, or their most recent contact $(n=27)$ on June 30, 2020.

\section{Immunohistochemical analysis}

Immunohistochemistry was employed to determine the intracellular localization and expression of all proteins. Immunohistochemical staining was performed using paraffin-embedded tissue. The tissue sections $(4 \mu \mathrm{m})$ were deparaffinized in xylene and rehydrated in a descending alcohol set followed by heated antigen retrieval with $10 \mathrm{mM}$ sodium citrate buffer (pH 6.0) or Tris-EDTA buffer (pH 8.0) for 5 or $30 \mathrm{~min}$, respectively. Coverplates ${ }^{\mathrm{TM}}$ (ThermoFisher Scientific) were also used. Endogenous peroxidase activity was suppressed with Peroxide Block (Zytomed Systems). Primary monoclonal antibodies were diluted with Antibody Diluent (Zytomed Systems). Sections were covered with antibody and incubated at $4{ }^{\circ} \mathrm{C}$ for $24 \mathrm{~h}$. Subsequently, ZytoChem Plus (HRP) Polymer Bulk Kit (Zytomed Systems) were used before staining with DAB (diaminobenzidin) Substrate Kit (Zytomed Systems). Gill's hematoxylin III (Carl Roth) was used as a counterstaining agent, including a 10 s hydrochloric acid bath (5\%) for differentiation. Sections were then dehydrated and mounted with EcoMount (Zytomed Systems).

Following primary antibodies were used: MST1 (1:150, Abcam (UK), ab51134), MST2 (1:100, Abcam (UK), ab52641), LATS1 (1:150, Abcam (UK), ab234820), LATS2 (1:50, Abcam (UK), ab135794), pLATS1 + 2 (1:50, Abcam (UK), ab111344), YAP (1:100, Abcam (UK), ab52771), pYAP-S127 (1:100, Abcam (UK), ab76252), 14-3-3- $\sigma$ (1:50, Abcam (UK), ab14123), TEAD1 (1:500, Abcam (UK), ab133533), TEAD2 (1:75, Abcam (UK), ab196669), TEAD3 (1:500, Abcam (UK), ab237766) and TEAD4 (1:250, Abcam (UK), ab97460).

\section{Methods of evaluation}

An immunoreactive score (IRS) was implemented for the evaluation of protein expression, which was based on the intensity and quantity of immune staining in the pancreatic cancer cells. The IRS score was applied as described by Kaemmerer and Remmele et al. (Kaemmerer et al. 2012; Remmele and Stegner 1987).

The intensity of staining was graded as negative (0), mild (1), moderate (2) and intense (3). The percentage of positive cells was evaluated as 0 (no positive cells), 1 ( $<10 \%$ positive cells), 2 (10-50\% positive cells), 3 (51-80\% positive cells) and 4 ( $>80 \%$ positive cells). The IRS score was obtained by multiplying these two individual scores. As a result, every tissue sample was classified into negative (IRS points 0-1), weak (2-3), mild (4-8) or strong (9-12). Two independent reviewers then evaluated the protein expression without prior knowledge of the patient characteristics. 


\section{Statistical analysis}

Differences in continuous variables were analyzed with the Mann-Whitney $U$ test and differences in proportions were analyzed with the Chi-square test or Fisher exact test. Overall and disease-free survival was evaluated with the Kaplan-Meier method. Univariate and multivariate Cox proportional hazards models were used to assess the effects of variables on OS and DFS and to also compute mortality hazard ratios (HR). The Spearman rank order correlation was used for the pairwise correlation analyses of expression between proteins. A two-sided $p$ value less than 0.05 was considered as statistically significant. All analyses were performed using SPSS Inc. (Chicago, IL, USA).

\section{Results}

\section{Study population}

A total of 103 patients who had been diagnosed with PDAC and undergone surgery between 2010 and 2018 were enrolled in this study. The patients had a median age of 67.8 years and 51 were female (49.5\%). Features are listed in Table 1. Eight patients (7.8\%) received neoadjuvant chemotherapy with FOLFIRINOX due to locally advanced PDAC. The majority of the tumours was located in the pancreas head $(78.6 \%)$. Due to the most common tumour location, a pancreaticoduodenectomy (PDPP) was performed in the most cases (67.9\%). Most patients suffered from a T3 stage (67.9\%), nodal-positive (75.7\%) and poorly differentiated (65.0\%) tumour. The study population included patients in all possible variations of tumour stages and progression. Forty-two patients (40.8\%) suffered from metastatic disease at the time of surgery. Of these metastasized patients, the majority presented with liver metastases $(83.3 \%)$, while four patients had distant lymph node metastasis $(9.5 \%)$ and three patients had peritoneal carcinomatosis (7.2\%). Seven of these patients were evaluated as not resectable during surgery. After surgery, 88 patients $(85.4 \%)$ were treated with adjuvant chemotherapy, mainly gemcitabine.

\section{Expression of kinases MST1/2, LATS1/2 and pLATS}

The Hippo pathway comprises of a core kinase cascade, starting with the activation of a pair of MST1/2, which phosphorylate and activate another pair of kinases-LATS1/2. A positive expression of all kinases was found in the majority of cases: MST1 was found in $71.8 \%$, MST2 in $84.5 \%$, LATS 1 in $89.3 \%$, LATS 2 in $66.0 \%$ and pLATS in $65.1 \%$. MST1, MST2 and LATS1 expression was upregulated compared with the corresponding healthy pancreatic tissue $(p<0.01$, Table 2$)$. In contrast, pLATS was downregulated in cancer cells $(p<0.01$, Table 2$)$. The association between the expression of kinases and tumour characteristics revealed significant correlations in our study (Table 1). In metastasized patients we observed a significantly lower IRS score of MST1, MST2 and pLATS $(p<0.01)$, which represents the active conformation of the Hippo pathway. In contrast, LATS 1 and LATS2 were upregulated in metastasized patients $(p<0.01)$.

Of the metastasized patients, 29 corresponding liver metastases were examined. We did not find any significant difference between the expression of all kinases in pancreatic cancer cells of the metastasized primary tumour and the cells in the corresponding metastasis (Table 2). Notably LATS2 was expressed more frequently in the healthy liver tissue compared to the pancreatic cancer cells within the liver parenchyma $(<0.01)$.

Alongside the metastatic status, MST2 IRS score was found to be significantly lower in tumours with lymphatic invasion $(p=0.04)$ and in tumours with a diameter larger than $3.5 \mathrm{~cm}(p<0.01)$. Furthermore, a lower IRS score of pLATS was significantly correlated with lymphatic invasion, nodal-positive and more undifferentiated tumours $(p<0.01)$.

\section{Expression of YAP, pYAP and 14-3-3}

Expression of pYAP was detected in the cytoplasm, while YAP was mainly expressed in the nucleus of pancreatic cancer cells (Fig. 1). Both components, YAP and pYAP, were upregulated in PDAC compared to the corresponding healthy pancreatic tissue $(p<0.01)$. We observed a higher IRS score of YAP in patients receiving neoadjuvant chemotherapy $(p<0.04$, Table 1B).

A lower expression of pYAP and the interacting 14-3-3 protein in pancreatic cancer cells was associated with the presence of metastases at time of surgery $(p<0.01$, Table 1B). In contrast, YAP was more frequently expressed in these metastasized patients $(p<0.01$, Table 1B). As already elucidated with the upstream kinases LATS1, LATS2 and pLATS, there was no significant difference regarding the expression of YAP, pYAP and 14-3-3 between the metastasized primary tumour and the relating liver metastases. Furthermore, the proteins had a similar expression in the surrounding liver parenchyma (Table 2).

\section{Expression of transcriptional factors TEAD1-4}

In the inactive Hippo pathway, YAP is located in the nucleus and can interact with transcription factors TEAD1, TEAD2, TEAD3 and TEAD4 resulting in cell growth and proliferation. Therefore, we evaluated the nuclear expression of TEAD1, TEAD2, TEAD3 and TEAD4. All forms of TEAD were found to be upregulated in PDAC compared with corresponding healthy pancreatic tissue (Table 2). 


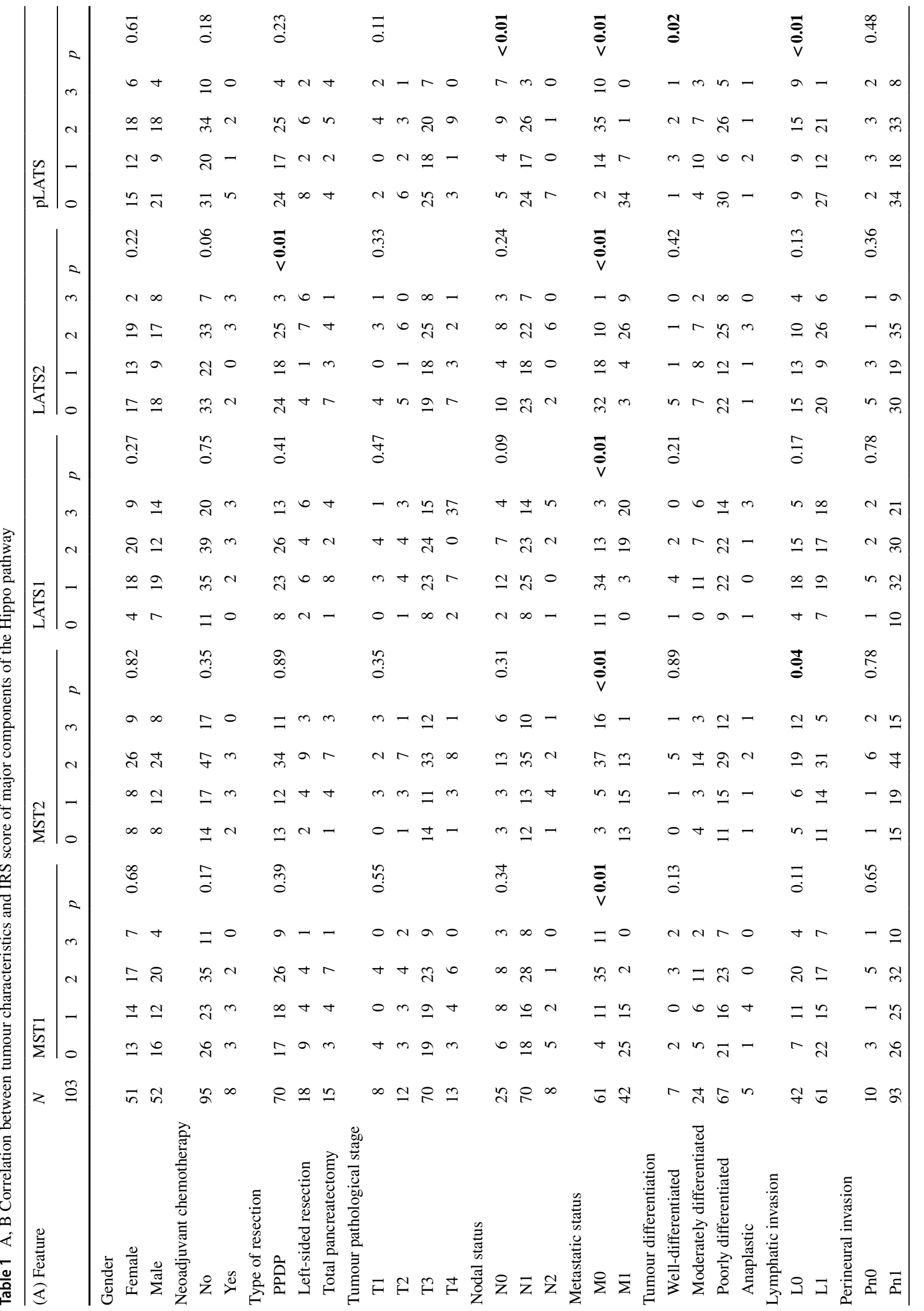




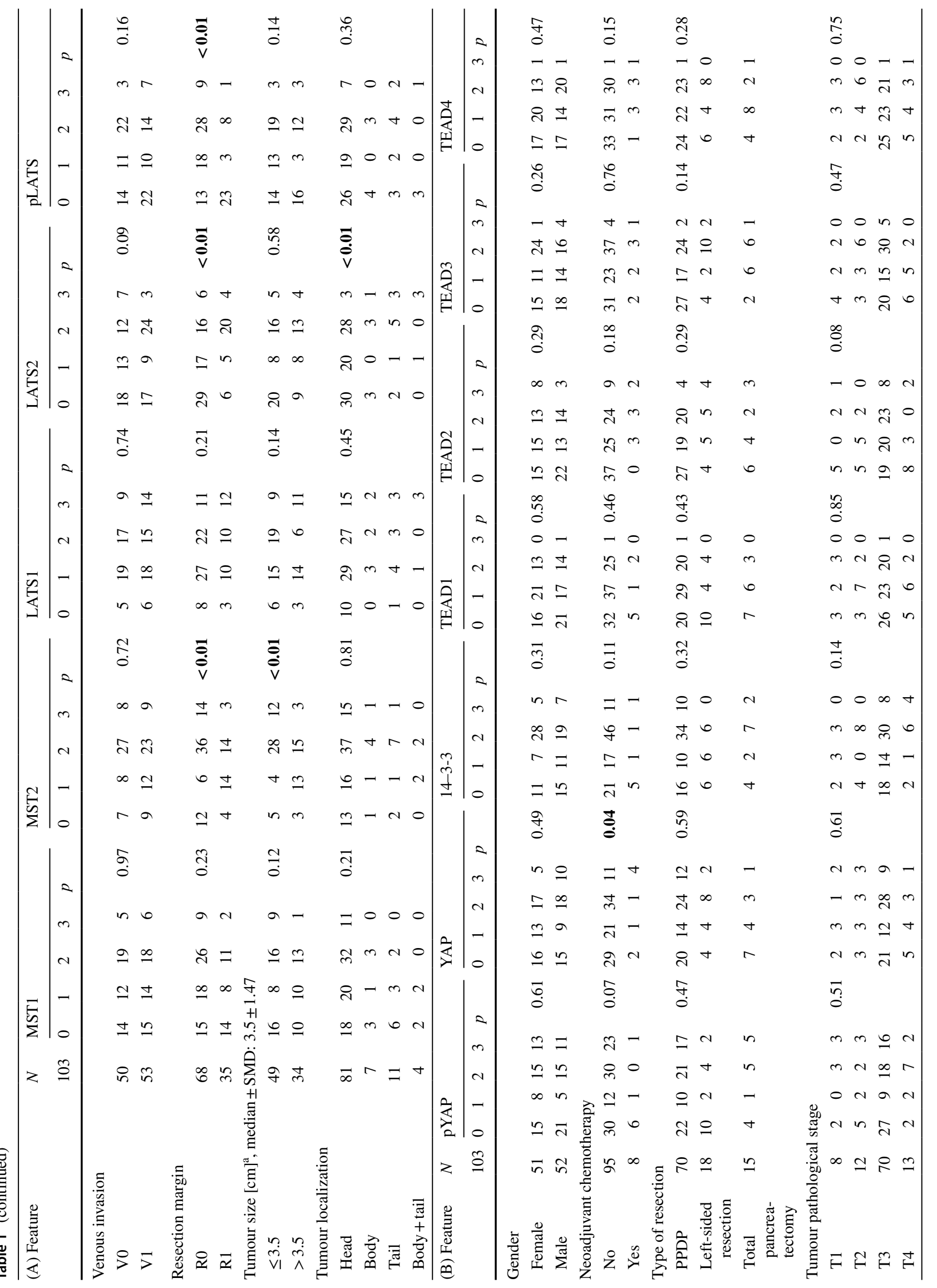




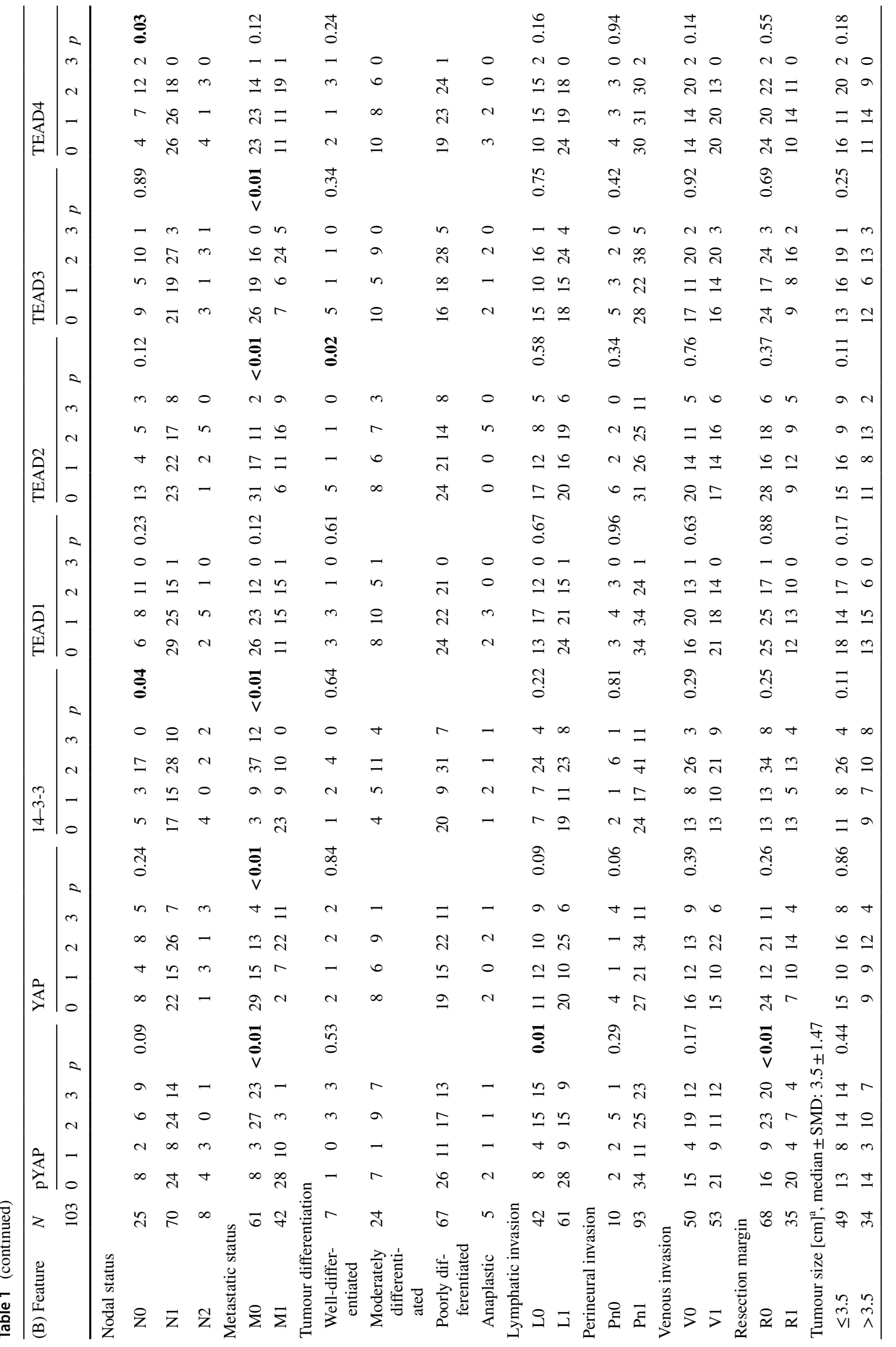


A significantly higher TEAD2 and TEAD3 expression was observed in metastasized patients $(p<0.01$, Table 1B). No significant associations were found for TEAD1, while TEAD4 was more frequently expressed in nodal-negative tumours $(p=0.03$, Table 1B).

The liver metastases showed similar intensities of expression, as found in metastasized primary tumours. However, TEAD1, TEAD2 and TEAD4, but not TEAD3, were upregulated in the liver metastases in comparison with the respective surrounding liver parenchyma (Table 2).

\section{Activity of the Hippo pathway as an indicator for post-surgical prognosis}

Data for overall survival was available for all 103 patients with 27 people $(26.2 \%)$ living at the end of the study. Data regarding the time of recurrence was available to us for 84 of the patients and of these 84 patients, 56 patients $(66.7 \%)$ suffered a recurrence. The majority $(66.1 \%)$ had liver metastases. Seven patients suffered lung metastases (12.5\%), five patients from peritoneal carcinomatosis $(8.9 \%)$ and another seven patients from local recurrence $(12.5 \%)$.

Focusing on the association between the activity of the Hippo pathway and the survival of the patients, we created a ratio of YAP and pYAP, which compared the IRS score directly between both parameters and is also representative of pathway activity. A higher IRS score of YAP than pYAP (YAP $>$ pYAP) resulted in a significantly shorter OS with a median survival of 13.0 months. In turn, a pYAP $>$ YAP ratio was prognostically favorable with a median OS of 28.0 months ( $p=0.003$, Fig. 2 h). Furthermore, patients with a mildly or strongly positive IRS score of pLATS $(p=0.037$, Fig. 2e) and pYAP ( $p=0.001$, Fig. 2f) had a significant longer OS. In contrast, an upregulation of transcription factor TEAD2 corresponds to a worse prognosis regarding the OS ( $p=0.025$, Fig. $2 \mathrm{k}$ ). However, the YAP expression itself was not significantly associated with the OS $(p=0.558$, Fig. 2g). In a multivariate analysis, pYAP expression (HR: $0.51 ; 95 \%$ CI $0.22-2.01 ; p=0.07)$ and metastatic status (HR: $0.47 ; 95 \%$ CI $0.18-1.22 ; p=0.03$ ) was associated with OS (Table 3).

The activity of the Hippo pathway seems to be an important factor in predicting the time until recurrence. As observed for the OS, a YAP > pYAP ratio was significantly associated with a shorter DFS than a pYA $>$ YAP ratio ( $p=0.004$, Fig. $3 \mathrm{~h}$ ). The median DFS in patients with a higher IRS score of YAP was 9.0 months, as compared with 17.0 months in patients with a pYAP $>$ YAP ratio. In addition, a negative or weakly positive IRS score of YAP itself was correlated with a shorter DFS ( $p=0.001$, Fig. 3g). Of all other components of the Hippo pathway, only LATS1 ( $p=0.013$, Fig. 3d) and TEAD1 ( $p=0.019$, Fig. 3k) had a statistical significance in predicting time until recurrence. 
Table 2 Overview of Hippo pathway proteins in PDAC, corresponding pancreatic tissue, liver metastasis and surrounding liver tissue of metastasized patients

\begin{tabular}{|c|c|c|c|c|c|c|c|c|c|}
\hline Antibody & PDAC & $\begin{array}{l}\text { Healthy } \\
\text { pancreatic } \\
\text { tissue }\end{array}$ & $p$ & PDAC & $\begin{array}{l}\text { Liver } \\
\text { metasta- } \\
\text { sis }\end{array}$ & $p$ & $\begin{array}{l}\text { Liver } \\
\text { metasta- } \\
\text { sis }\end{array}$ & $\begin{array}{l}\text { Healthy } \\
\text { liver tissue }\end{array}$ & $p$ \\
\hline \multicolumn{10}{|l|}{ MST1 } \\
\hline Negative & 29 & 18 & \multirow[t]{4}{*}{$<0.01$} & 17 & 23 & \multirow[t]{4}{*}{0.64} & 23 & 5 & \multirow[t]{4}{*}{0.33} \\
\hline Weak & 26 & 45 & & 11 & 3 & & 3 & 10 & \\
\hline Mild & 37 & 35 & & 1 & 2 & & 2 & 8 & \\
\hline Strong & 11 & 5 & & 0 & 1 & & 1 & 6 & \\
\hline \multicolumn{10}{|l|}{ MST2 } \\
\hline Negative & 16 & 13 & \multirow[t]{4}{*}{$<0.01$} & 9 & 16 & \multirow[t]{4}{*}{0.08} & 16 & 13 & \multirow[t]{4}{*}{0.19} \\
\hline Weak & 20 & 20 & & 11 & 11 & & 11 & 15 & \\
\hline Mild & 50 & 64 & & 9 & 1 & & 1 & 0 & \\
\hline Strong & 17 & 6 & & 0 & 1 & & 1 & 1 & \\
\hline \multicolumn{10}{|l|}{ LATS1 } \\
\hline Negative & 11 & 1 & \multirow[t]{4}{*}{$<0.01$} & 2 & 1 & \multirow[t]{4}{*}{0.89} & 1 & 1 & \multirow[t]{4}{*}{0.83} \\
\hline Weak & 37 & 34 & & 6 & 7 & & 7 & 8 & \\
\hline Mild & 32 & 68 & & 13 & 15 & & 15 & 15 & \\
\hline Strong & 23 & 0 & & 8 & 6 & & 6 & 5 & \\
\hline \multicolumn{10}{|l|}{ LATS2 } \\
\hline Negative & 35 & 7 & \multirow[t]{4}{*}{0.12} & 2 & 3 & \multirow[t]{4}{*}{0.35} & 3 & 1 & \multirow[t]{4}{*}{$<0.01$} \\
\hline Weak & 22 & 38 & & 5 & 10 & & 10 & 5 & \\
\hline Mild & 36 & 54 & & 18 & 15 & & 15 & 22 & \\
\hline Strong & 10 & 4 & & 4 & 1 & & 1 & 1 & \\
\hline \multicolumn{10}{|l|}{ pLATS } \\
\hline Negative & 30 & 6 & \multirow[t]{4}{*}{$<0.01$} & 23 & 23 & \multirow[t]{4}{*}{0.58} & 23 & 10 & \multirow[t]{4}{*}{0.08} \\
\hline Weak & 12 & 25 & & 6 & 3 & & 3 & 7 & \\
\hline Mild & 22 & 35 & & 0 & 3 & & 3 & 12 & \\
\hline Strong & 10 & 8 & & 0 & 0 & & 0 & 0 & \\
\hline \multicolumn{10}{|l|}{ pYAP } \\
\hline Negative & 36 & 33 & $<0.01$ & 18 & 20 & 0.15 & 20 & 18 & 0.72 \\
\hline Weak & 13 & 38 & & 8 & 7 & & 7 & 9 & \\
\hline Mild & 28 & 26 & & 2 & 2 & & 2 & 2 & \\
\hline Strong & 23 & 3 & & 1 & 0 & & 0 & 0 & \\
\hline YAP & & & & & & & & & \\
\hline Negative & 31 & 48 & $<0.01$ & 2 & 6 & 0.06 & 6 & 12 & 0.08 \\
\hline Weak & 22 & 36 & & 6 & 4 & & 4 & 6 & \\
\hline Mild & 35 & 19 & & 15 & 13 & & 13 & 11 & \\
\hline Strong & 15 & 0 & & 6 & 6 & & 6 & 0 & \\
\hline $14-3-3$ & & & & & & & & & \\
\hline Negative & 26 & 18 & $<0.01$ & 16 & 21 & 0.58 & 21 & 11 & 0.08 \\
\hline Weak & 18 & 27 & & 6 & 6 & & 6 & 12 & \\
\hline Mild & 47 & 49 & & 7 & 2 & & 2 & 6 & \\
\hline Strong & 12 & 9 & & 0 & 0 & & 0 & 0 & \\
\hline TEAD1 & & & & & & & & & \\
\hline Negative & 37 & 60 & $<0.01$ & 4 & 20 & 0.26 & 20 & 27 & $<0.01$ \\
\hline Weak & 38 & 32 & & 9 & 5 & & 5 & 2 & \\
\hline Mild & 27 & 11 & & 15 & 3 & & 3 & 0 & \\
\hline Strong & 1 & 0 & & 1 & 1 & & 1 & 0 & \\
\hline
\end{tabular}


Table 2 (continued)

\begin{tabular}{|c|c|c|c|c|c|c|c|c|c|}
\hline Antibody & PDAC & $\begin{array}{l}\text { Healthy } \\
\text { pancreatic } \\
\text { tissue }\end{array}$ & $p$ & PDAC & $\begin{array}{l}\text { Liver } \\
\text { metasta- } \\
\text { sis }\end{array}$ & $p$ & $\begin{array}{l}\text { Liver } \\
\text { metasta- } \\
\text { sis }\end{array}$ & $\begin{array}{l}\text { Healthy } \\
\text { liver tissue }\end{array}$ & $p$ \\
\hline \multicolumn{10}{|l|}{ TEAD2 } \\
\hline Negative & 37 & 45 & $<0.01$ & 2 & 5 & 0.67 & 5 & 5 & $<0.01$ \\
\hline Weak & 28 & 23 & & 9 & 6 & & 6 & 11 & \\
\hline Mild & 27 & 30 & & 11 & 15 & & 15 & 12 & \\
\hline Strong & 11 & 5 & & 7 & 3 & & 3 & 1 & \\
\hline \multicolumn{10}{|l|}{ TEAD3 } \\
\hline Negative & 33 & 72 & $<0.01$ & 4 & 9 & 0.55 & 9 & 13 & 0.55 \\
\hline Weak & 25 & 26 & & 5 & 8 & & 8 & 12 & \\
\hline Mild & 40 & 5 & & 16 & 11 & & 11 & 4 & \\
\hline Strong & 5 & 0 & & 4 & 1 & & 1 & 0 & \\
\hline \multicolumn{10}{|l|}{ TEAD4 } \\
\hline Negative & 34 & 76 & 0.02 & 7 & 13 & 0.32 & 13 & 17 & 0.03 \\
\hline Weak & 34 & 22 & & 7 & 11 & & 11 & 10 & \\
\hline Mild & 33 & 5 & & 15 & 5 & & 5 & 2 & \\
\hline Strong & 2 & 9 & & 0 & 0 & & 0 & 0 & \\
\hline
\end{tabular}

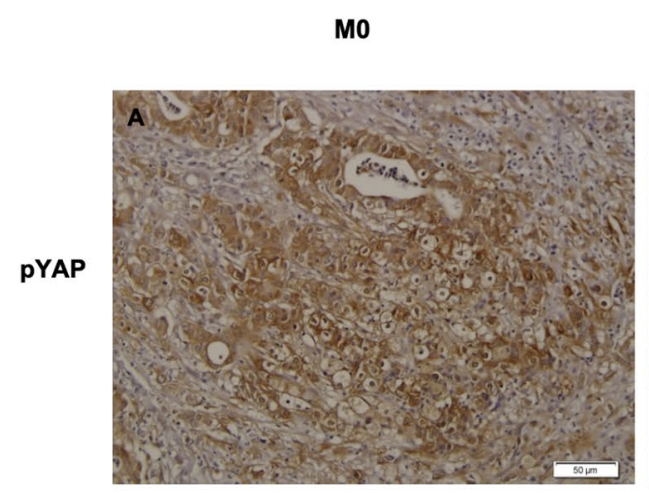

M1

Liver metastases
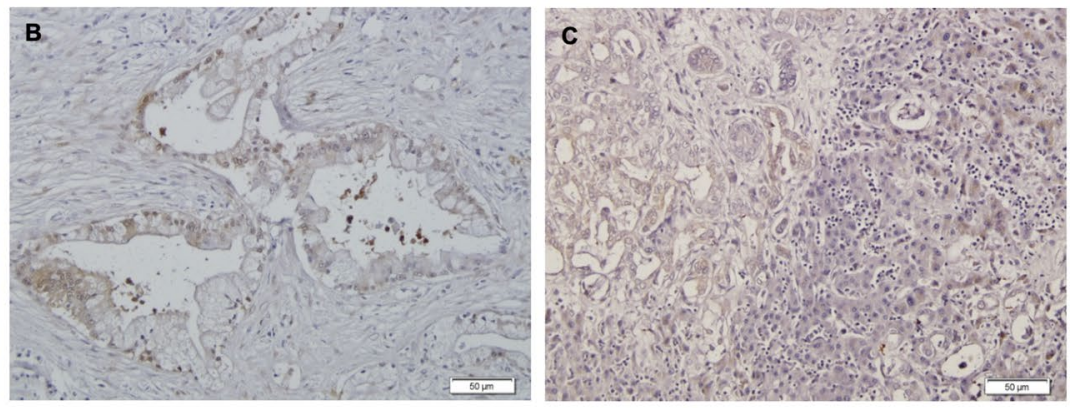

YAP
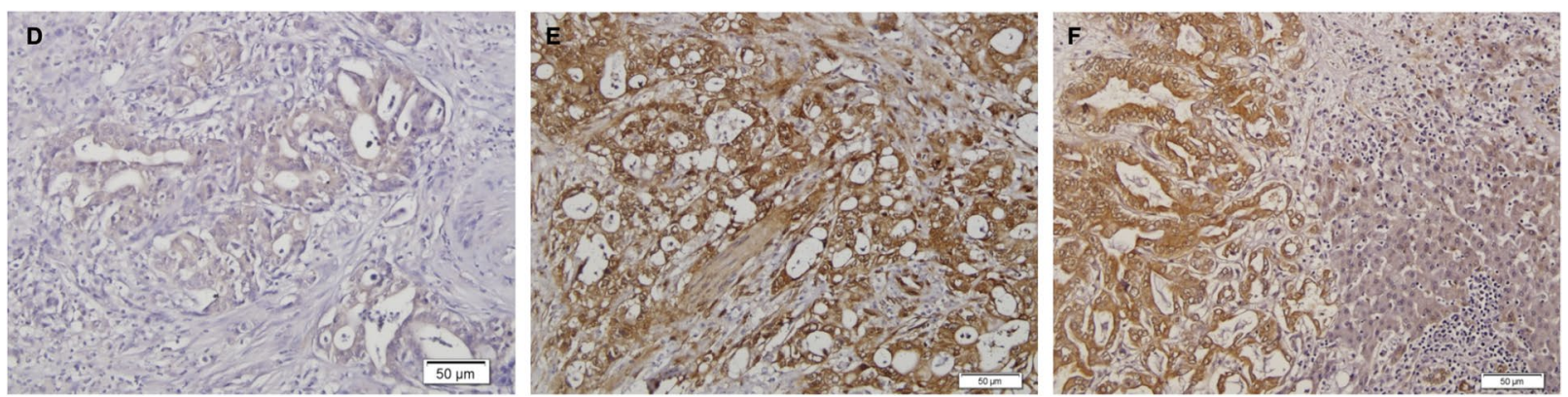

Fig. 1 a-f Immunohistochemical staining of pYAP and YAP. Representative images of pYAP and YAP in non-metastasized (a, d) and metastasized patients $(\mathbf{b}, \mathbf{e})$ with their corresponding liver metastases $(\mathbf{c}, \mathbf{f})$. Scale bar, $50 \mu \mathrm{m}$

Applying multivariate analysis, ratio YAP > pYAP (HR: 7.39; 95\% CI 1.89-29.5; $p=0.005$ ), YAP expression (HR: 0.2 ; 95\% CI 0.04-0.96; $p=0.04$ ), pYAP expression (HR: $5.55 ; 95 \%$ CI $1.09-28.4 ; p=0.04)$, tumour pathological stage (HR: 3.23 ; 95\% CI $1.57-6.63 ; p=0.003$ ) and nodal status (HR: 0.09 ; 95\% CI 0.03-0.36; $p=0.001$ ) was associated with DFS (Table 4). 
A

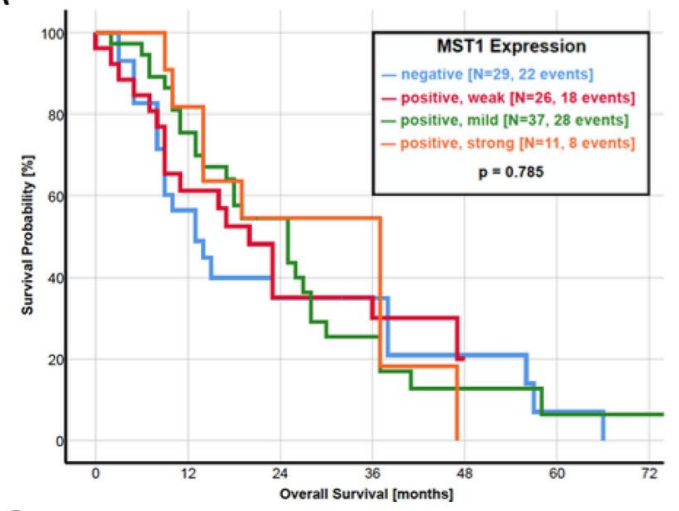

C

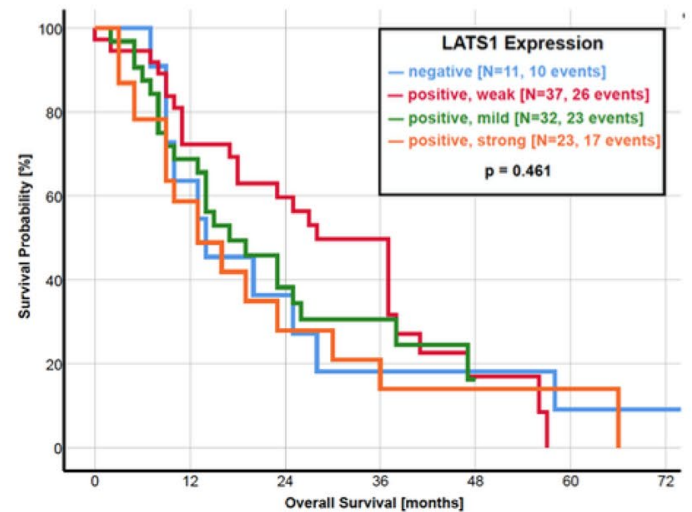

$\mathrm{E}$

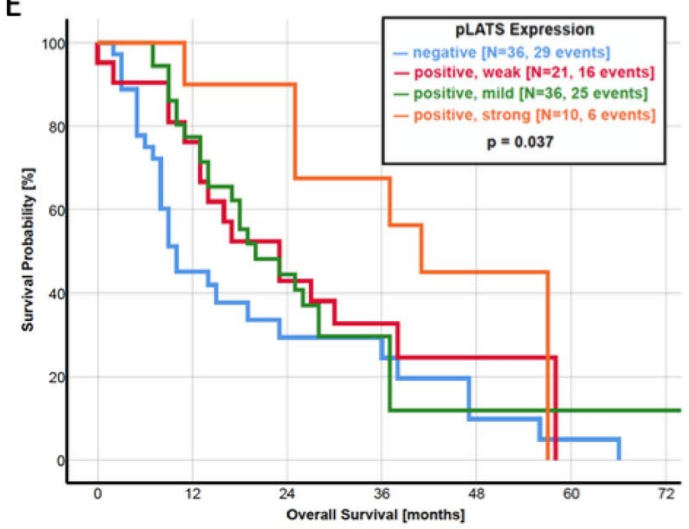

G

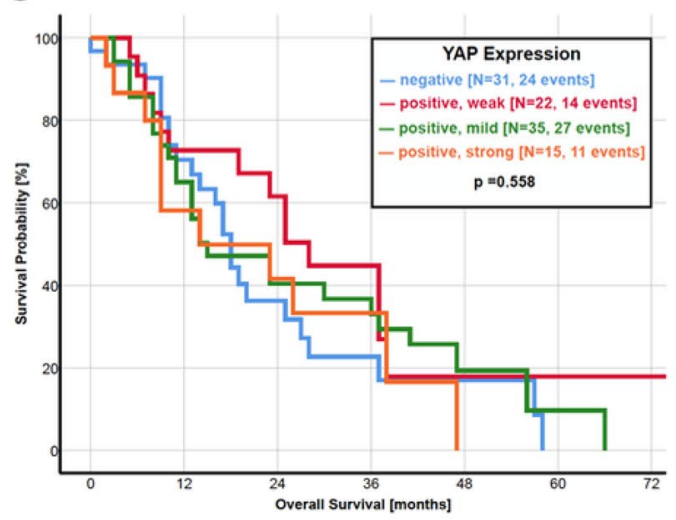

B

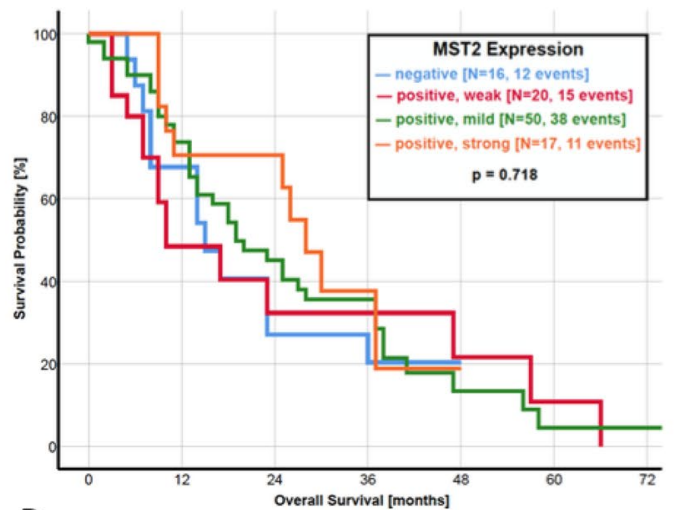

D
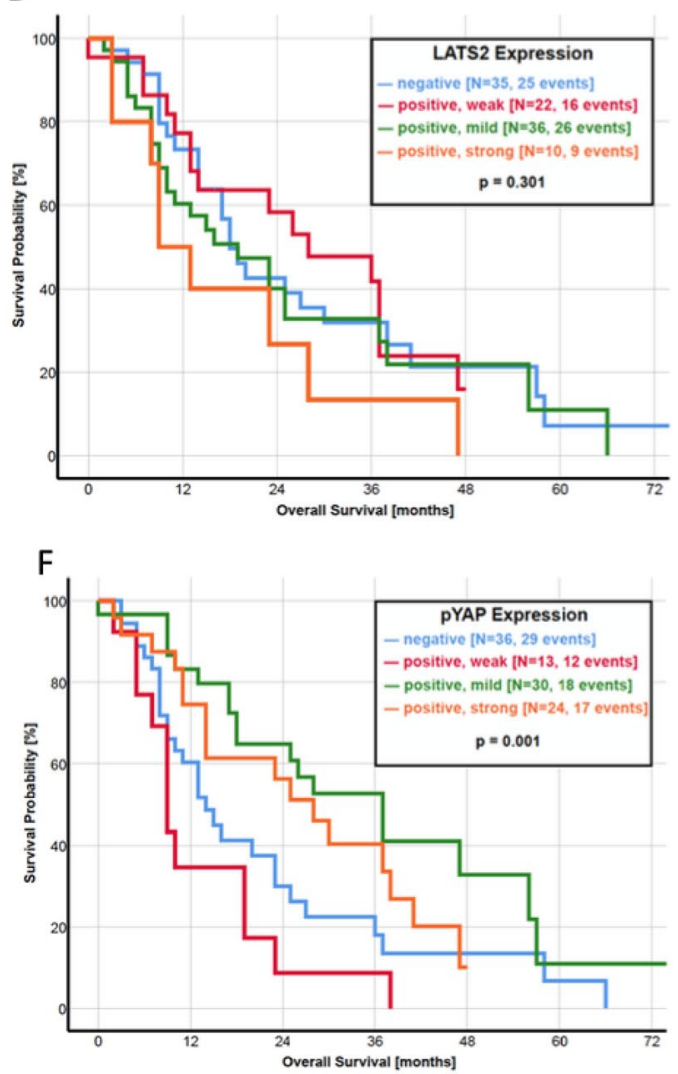

$\mathrm{H}$

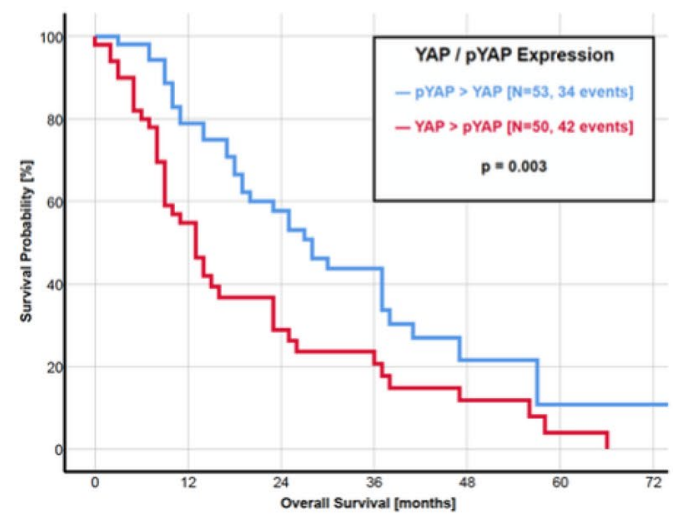

Fig. 2 a-m Kaplan-Meier curves of overall survival for each protein of the Hippo pathway. a MST1, b MST2, $\mathbf{c}$ LATS1, $\mathbf{d}$ LATS2, e pLATS, $\mathbf{f}$ pYAP, $\mathbf{g}$ YAP, $\mathbf{h}$ ratio YAP/pYAP, $\mathbf{i}$ 14-3-3 protein, $\mathbf{j}$ TEAD1, $\mathbf{k}$ TEAD2, $\mathbf{l}$ TEAD3 and $\mathbf{m}$ TEAD4 

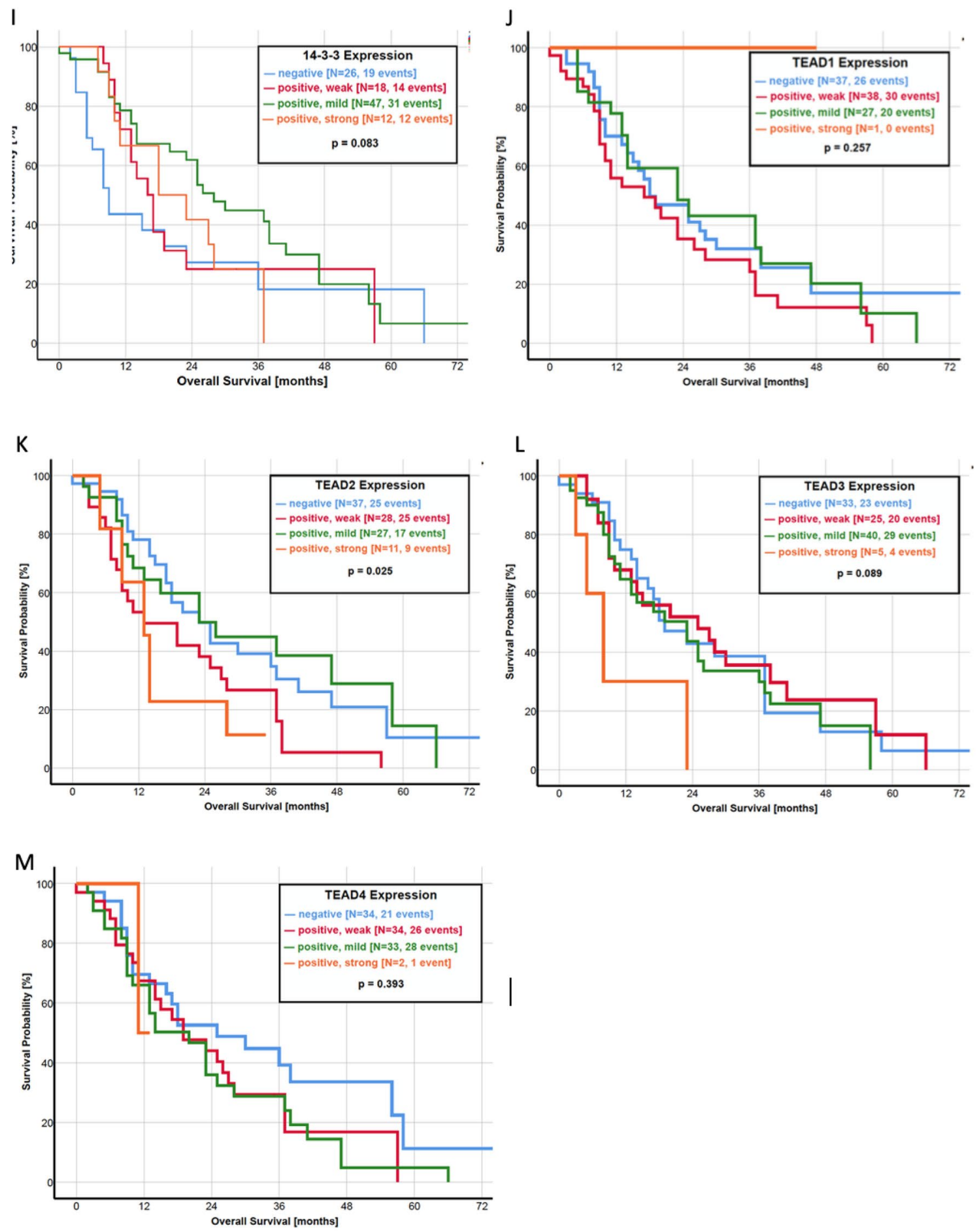

Fig. 2 (continued)

\section{Discussion}

PDAC is one of the most aggressive oncological diseases with limited therapeutic options for patients who often present with metastases at the time of diagnosis. This renders the prognosis by and large as unfavorable. Finding an efficient therapy to inhibit further metastases remains an almost insurmountable challenge but is necessary for improving patient survival. Therefore, understanding the molecular mechanisms that underlie metastatic processes is fundamental. In our study, we used immunohistochemical techniques to assess expression levels of the most important 
Table 3 Cox proportional hazard for overall survival $(n=103)$

\begin{tabular}{|c|c|c|c|c|c|c|}
\hline \multirow[t]{2}{*}{ Variable } & \multirow[t]{2}{*}{ No. } & \multirow{2}{*}{$\begin{array}{l}\text { Median OS } \\
\text { [months] }\end{array}$} & \multicolumn{2}{|l|}{ Univariate } & \multicolumn{2}{|l|}{ Multivariate } \\
\hline & & & Hazard ratio $(95 \% \mathrm{CI})$ & $p$ value & Hazard ratio $(95 \% \mathrm{CI})$ & $p$ value \\
\hline \multicolumn{7}{|l|}{ Ratio pYAP/YAP expression } \\
\hline pYAP $>$ YAP & 53 & 19.0 & 1.00 & & 1.00 & \\
\hline YAP $>$ pYAP & 50 & 13.0 & $1.34(0.86-2.11)$ & 0.20 & $1.57(0.53-4.71)$ & 0.42 \\
\hline \multicolumn{7}{|l|}{ YAP expression } \\
\hline Negative & 31 & 17.0 & 1.00 & & 1.00 & \\
\hline Positive, weak & 22 & 24.0 & $0.66(0.34-1.28)$ & 0.22 & $0.34(0.13-0.89)$ & 0.78 \\
\hline Positive, mild & 35 & 14.0 & $0.89(0.51-1.56)$ & 0.69 & $1.19(0.16-1.54)$ & 0.12 \\
\hline Positive, strong & 15 & 13.0 & $1.01(0.52-2.20)$ & 0.84 & $1.03(0.19-2.43)$ & 0.49 \\
\hline \multicolumn{7}{|l|}{ pYAP expression } \\
\hline Negative & 36 & 13.0 & 1.00 & & 1.00 & \\
\hline Positive, weak & 13 & 9.0 & $1.79(0.90-3.56)$ & 0.09 & $1.27(0.49-3.24)$ & 0.62 \\
\hline Positive, mild & 28 & 25.5 & $0.47(0.26-0.84)$ & 0.01 & $0.41(0.17-0.99)$ & 0.04 \\
\hline Positive, strong & 23 & 21.0 & $0.69(0.36-1.23)$ & 0.19 & $1.42(0.40-4.96)$ & 0.59 \\
\hline \multicolumn{7}{|l|}{ Tumour pathological stage } \\
\hline $\mathrm{T} 1$ & 8 & 19.0 & 1.00 & & 1.00 & \\
\hline $\mathrm{T} 2$ & 12 & 10.0 & $1.66(0.39-6.97)$ & 0.49 & $0.94(0.19-4.47)$ & 0.94 \\
\hline $\mathrm{T} 3$ & 70 & 9.0 & $2.64(0.83-8.46)$ & 0.10 & $1.30(0.37-4.62)$ & 0.69 \\
\hline $\mathrm{T} 4$ & 13 & 13.0 & $2.74(0.75-10.1)$ & 0.13 & $2.14(0.56-8.23)$ & 0.27 \\
\hline \multicolumn{7}{|l|}{ Nodal status } \\
\hline No & 25 & 23.0 & 1.00 & & 1.00 & \\
\hline N1 & 70 & 16.0 & $1.74(0.95-3.19)$ & 0.08 & $1.90(0.94-3.85)$ & 0.13 \\
\hline $\mathrm{N} 2$ & 8 & 9.0 & $2.85(0.91-8.98)$ & 0.07 & $3.09(0.84-11.4)$ & 0.52 \\
\hline \multicolumn{7}{|l|}{ Metastasis status } \\
\hline M0 & 61 & 20.0 & 1.00 & & 1.00 & \\
\hline M1 & 42 & 11.5 & $1.66(1.05-2.62)$ & 0.03 & $2.19(0.71-6.83)$ & 0.17 \\
\hline \multicolumn{7}{|l|}{ Tumour differentiation } \\
\hline Well-differentiated & 7 & 33.0 & 1.00 & & 1.00 & \\
\hline Moderately differentiated & 24 & 20.0 & $2.19(0.72-6.65)$ & 0.17 & $2.06(0.58-7.33)$ & 0.26 \\
\hline Poorly differentiated & 67 & 14.0 & $3.10(1.10-8.65)$ & $\mathbf{0 . 0 3}$ & $2.65(0.84-8.39)$ & 0.09 \\
\hline Anaplastic & 5 & 16.0 & $1.96(0.43-8.87)$ & 0.38 & $1.51(0.28-8.23$ & 0.64 \\
\hline \multicolumn{7}{|l|}{ Resection margin } \\
\hline R0 & 68 & 17.0 & 1.00 & & 1.00 & \\
\hline R1 & 35 & 14.0 & $1.24(0.77-2.01)$ & 0.37 & $1.08(0.61-1.92)$ & 0.78 \\
\hline
\end{tabular}

CI confidence interval

Hippo pathway components in 103 patients diagnosed with PDAC and treated with curative intention at our department. To the best of our knowledge, this is the largest cohort study investigating all major components of the Hippo pathway and correlating expression levels with clinicopathological results including OS and DFS.

The Hippo pathway is known for regulating cell proliferation, tissue homeostasis and organ size. Its role has broadened in cancer research in the past decade and it has been found to be a promoter of tumorigenesis and tumour migration (van Rensburg and Yang 2016; Han 2019; Moroishi et al. 2015; Lei et al. 2008). There is evidence that an inactivated pathway results in a higher nuclear YAP expression and in turn an unfavorable prognosis. All of this incurs a higher probability of spread of metastases in numerous malignancies (van Rensburg and Yang 2016; Zygulska et al. 2017; Yu et al. 2015; Harvey et al. 2013). Focusing on PDAC, Allende et al. associated a YAP overexpression with liver metastases and a poorer survival under 30 months in 64 curative treated patients (Salcedo Allende et al. 2017). Furthermore, different studies emphasize the importance of a YAP-driven cancer progression in PDAC in vitro and in vivo (Xie et al. 2015; Yang et al. 2015; Diep et al. 2012; Kapoor et al. 2014).

Returning to our study, we observed a significant upregulation of nearly all Hippo pathway components, except 
A

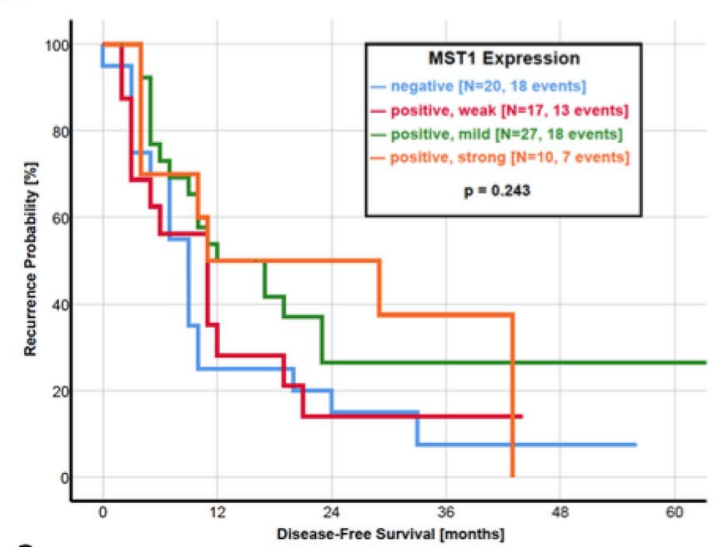

C

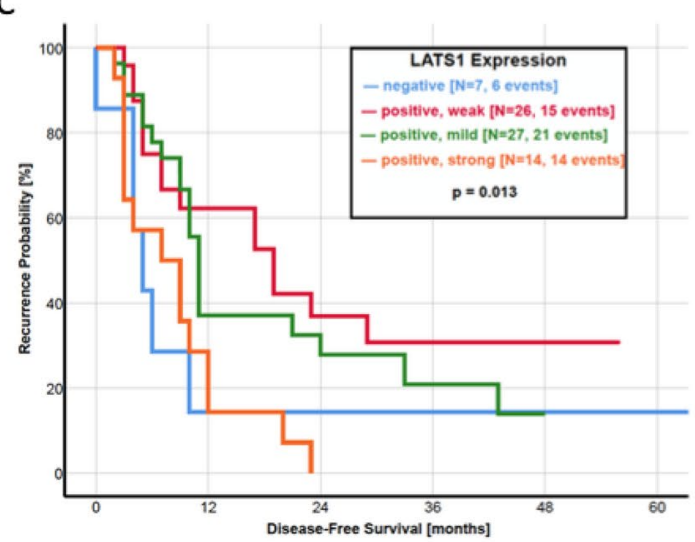

$E$

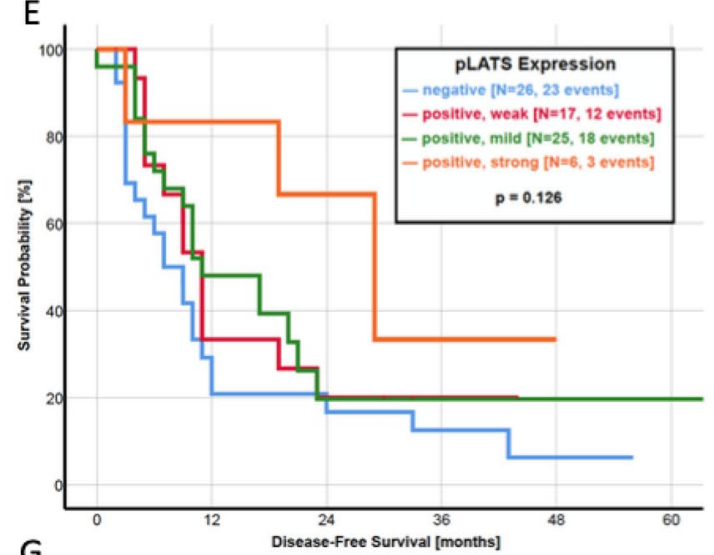

G

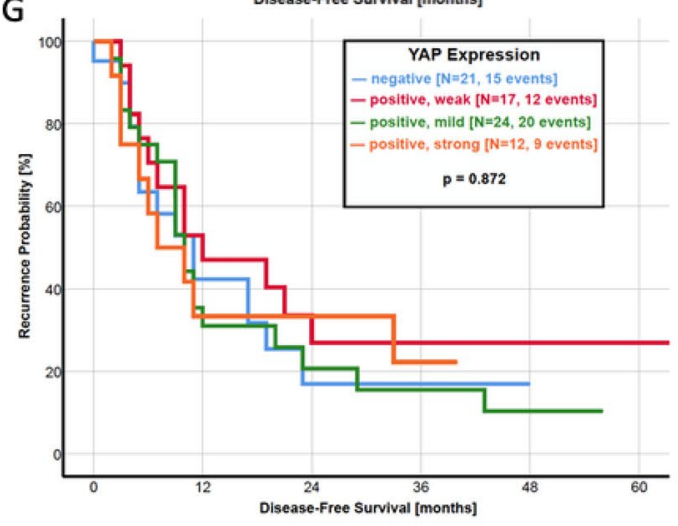

B

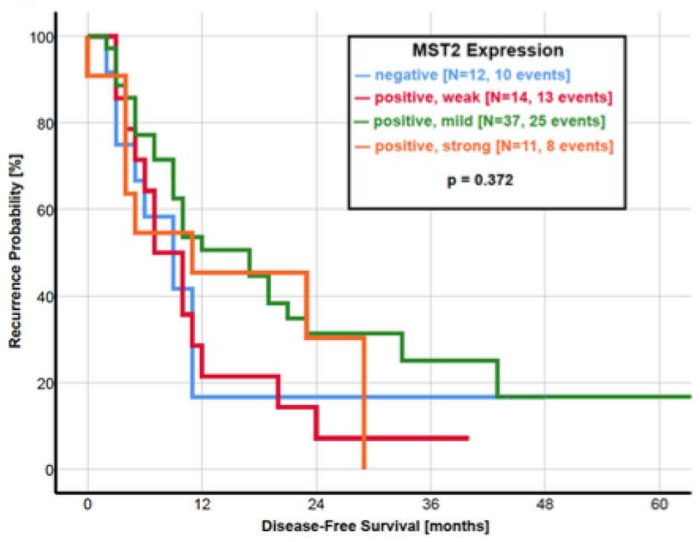

D

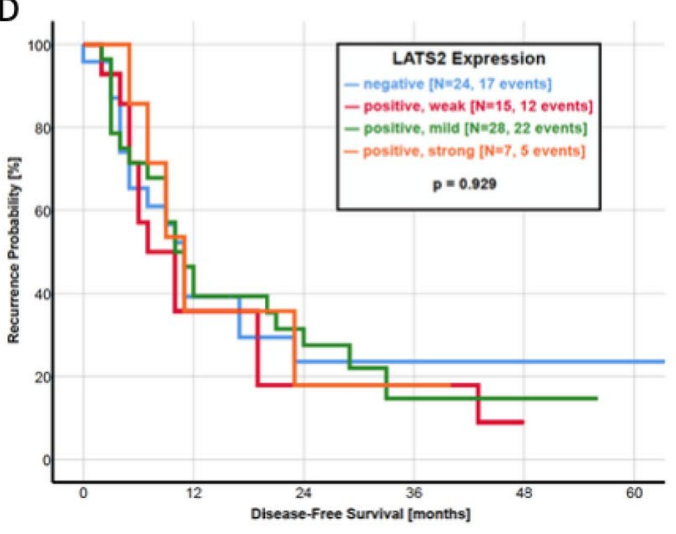

$\mathrm{F}$
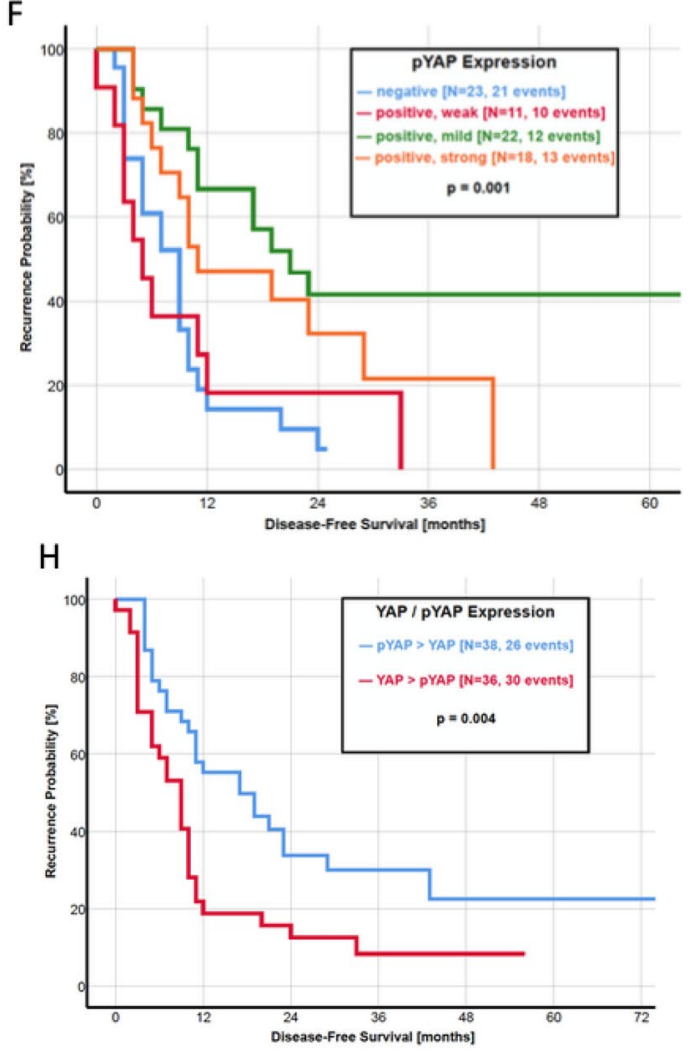

Fig. 3 a-n Kaplan-Meier curves of disease-free survival for HSP27 and each protein of the Hippo pathway. a HSP27, b MST1, c MST2, d LATS1, $\mathbf{e}$ LATS2, $\mathbf{f}$ pLATS, $\mathbf{g}$ pYAP, $\mathbf{h}$ YAP, $\mathbf{i}$ ratio YAP/pYAP, $\mathbf{j}$ 14-3-3 protein, $\mathbf{k}$ TEAD1, $\mathbf{I}$ TEAD2, $\mathbf{m}$ TEAD3 and $\mathbf{n}$ TEAD4 

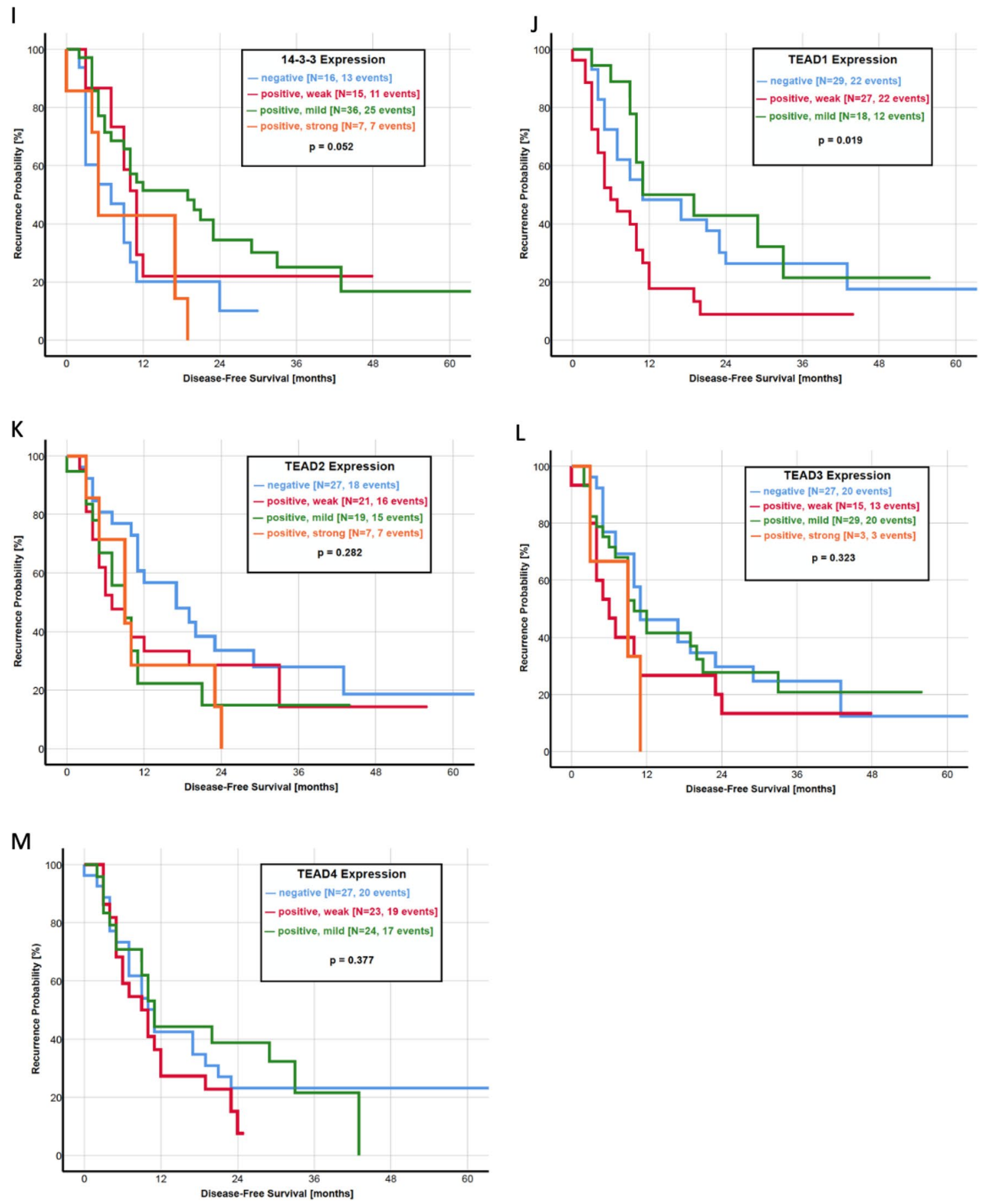

Fig. 3 (continued)

LATS2, in PDAC compared to healthy pancreatic tissue. Regarding the impact of the Hippo pathway upon tumour characteristics, we found a highly significant inactive shift in patients with metastases (Table 1). The proteins MST1, MST2, pLATS, pYAP and 14-3-3, representing the active pathway, were more frequently expressed in nonmetastasized patients. In turn, we observed a significant upregulation of LATS1, LATS2 and YAP in patients suffering metastases. These results are comparable to previous findings by Allende et al. where YAP was found to be overexpressed in metastasized patients (Salcedo Allende et al. 2017). Our results confirm the involvement of the whole Hippo pathway in metastatic processes of PDAC and proves previous experimental results in a real-life cohort study (Xie 
Table 4 Cox proportional hazard model for disease-free survival $(n=75)$

\begin{tabular}{|c|c|c|c|c|c|c|}
\hline \multirow[t]{2}{*}{ Variable } & \multirow[t]{2}{*}{ No. } & \multirow{2}{*}{$\begin{array}{l}\text { Median DFS } \\
\text { [months] }\end{array}$} & \multicolumn{2}{|l|}{ Univariate } & \multicolumn{2}{|l|}{ Multivariate } \\
\hline & & & Hazard ratio $(95 \% \mathrm{CI})$ & $p$ value & Hazard ratio $(95 \% \mathrm{CI})$ & $p$ value \\
\hline \multicolumn{7}{|l|}{ Ratio pYAP/YAP expression } \\
\hline pYAP $>$ YAP & 39 & 11.0 & 1.00 & & 1.00 & \\
\hline YAP $>$ pYAP & 36 & 9.0 & $1.26(0.75-2.14)$ & 0.39 & $3.18(0.62-16.3)$ & 0.02 \\
\hline \multicolumn{7}{|l|}{ YAP expression } \\
\hline Negative & 21 & 9.0 & 1.00 & & 1.00 & \\
\hline Positive, weak & 17 & 12.0 & $0.77(0.36-1.65)$ & 0.49 & $0.57(0.13-2.50)$ & 0.45 \\
\hline Positive, mild & 24 & 9.5 & $1.01(0.52-1.98)$ & 0.97 & $0.93(0.17-5.24)$ & 0.94 \\
\hline Positive, strong & 13 & 10.0 & $1.71(0.69-3.09)$ & 0.12 & $1.92(0.24-15.3)$ & 0.04 \\
\hline \multicolumn{7}{|l|}{ pYAP expression } \\
\hline Negative & 24 & 8.5 & 1.00 & & 1.00 & \\
\hline Positive, weak & 11 & 5.0 & $1.01(0.47-2.14)$ & 0.99 & $0.33(0.09-1.25)$ & 0.10 \\
\hline Positive, mild & 22 & 18.0 & $0.27(0.13-0.57)$ & $<0.01$ & $0.10(0.03-0.35)$ & $<0.01$ \\
\hline Positive, strong & 18 & 10.5 & $0.48(0.24-0.98)$ & 0.04 & $0.27(0.04-1.65)$ & 0.16 \\
\hline \multicolumn{7}{|l|}{ Tumour pathological stage } \\
\hline $\mathrm{T} 1$ & 7 & 19.0 & 1.00 & & 1.00 & \\
\hline $\mathrm{T} 2$ & 11 & 10.0 & $2.69(0.71-10.2)$ & 0.14 & $1.83(0.34-9.75)$ & 0.48 \\
\hline $\mathrm{T} 3$ & 50 & 9.0 & $2.62(0.81-8.50)$ & 0.11 & $1.72(0.44-6.70)$ & 0.44 \\
\hline $\mathrm{T} 4$ & 7 & 13.0 & $3.83(0.95-15.4)$ & 0.06 & $6.08(1.15-32.3)$ & $\mathbf{0 . 0 3}$ \\
\hline \multicolumn{7}{|l|}{ Nodal status } \\
\hline N0 & 18 & 18.0 & 1.00 & & 1.00 & \\
\hline N1 & 49 & 10.0 & $1.63(0.81-3.29)$ & 0.17 & $2.03(0.87-4.70)$ & 0.10 \\
\hline $\mathrm{N} 2$ & 8 & 3.0 & $6.91(2.60-18.3)$ & $<0.01$ & $9.59(2.52-36.5)$ & $<0.01$ \\
\hline \multicolumn{7}{|l|}{ Metastasis status } \\
\hline M0 & 44 & 11.0 & 1.00 & & 1.00 & \\
\hline M1 & 31 & 9.0 & $1.62(0.95-2.75)$ & 0.07 & $1.17(0.22-6.12)$ & 0.85 \\
\hline \multicolumn{7}{|l|}{ Tumour differentiation } \\
\hline Well-differentiated & 4 & 32.5 & 1.00 & & & \\
\hline Moderately differentiated & 18 & 11.5 & $6.31(0.82-48.5)$ & 0.07 & $6.92(0.77-62.1)$ & 0.08 \\
\hline Poorly differentiated & 51 & 9.0 & $7.92(1.08-58.2)$ & 0.04 & $7.55(0.89-64.4)$ & 0.06 \\
\hline Anaplastic & 2 & 22.0 & $3.42(0.21-55.2)$ & 0.39 & $9.04(0.41-200.6)$ & 0.16 \\
\hline \multicolumn{7}{|l|}{ Resection margin } \\
\hline R0 & 50 & 10.0 & 1.00 & & 1.00 & \\
\hline R1 & 25 & 10.0 & $1.09(0.63-1.91)$ & 0.74 & $1.77(0.97-3.23)$ & 0.08 \\
\hline
\end{tabular}

CI confidence interval

et al. 2015; Yang et al. 2015; Wei et al. 2017; Yuan et al. 2016). In addition, we observed similar expression levels of all proteins in the relating liver metastases compared to their metastasized primary tumours. When comparing the expression of the metastasis with the surrounding liver tissue, we could not find a significant difference indicating a dysregulation of the Hippo pathway in the whole liver parenchyma. A supposed predisposition for more liver metastases growing but not detectable at time of surgery is hypothesized.

In the current literature, only three studies investigate the impact of Hippo pathway components on patient survival. Allende et al. found a significantly lower expression of YAP in patients with an OS under 30 months, but no differences in Kaplan-Meier analysis of OS and DFS (Salcedo Allende et al. 2017). A recently published study by Zhou et al. revealed YAP as an independent prognostic marker as a higher protein expression was associated with a shorter OS and DFS in 140 patients (Zhou et al. 2020). Another study led by Rozengurt et al. identified multiple YAP/TEADregulated genes as predictors with unfavorable survival by using the Human Protein Atlas (Rozengurt et al. 2018). As our study presents all of the important Hippo pathway components in the largest study population to this date, we correlated the expression of every single protein with the OS and DFS. Kaplan-Meier analysis revealed a favorable OS in patients with a higher expression of pLATS and pYAP 
Fig. 4 Illustration of the pathway in non-metastasized and metastasized patients according to our immunohistochemical results. $p$ value refers to the difference of protein expression in regard to the metastatic status. Correlations are shown between expression of pathway components and their immediate downstream targets. Spearman rank order correlation was used for the pairwise correlation analyses

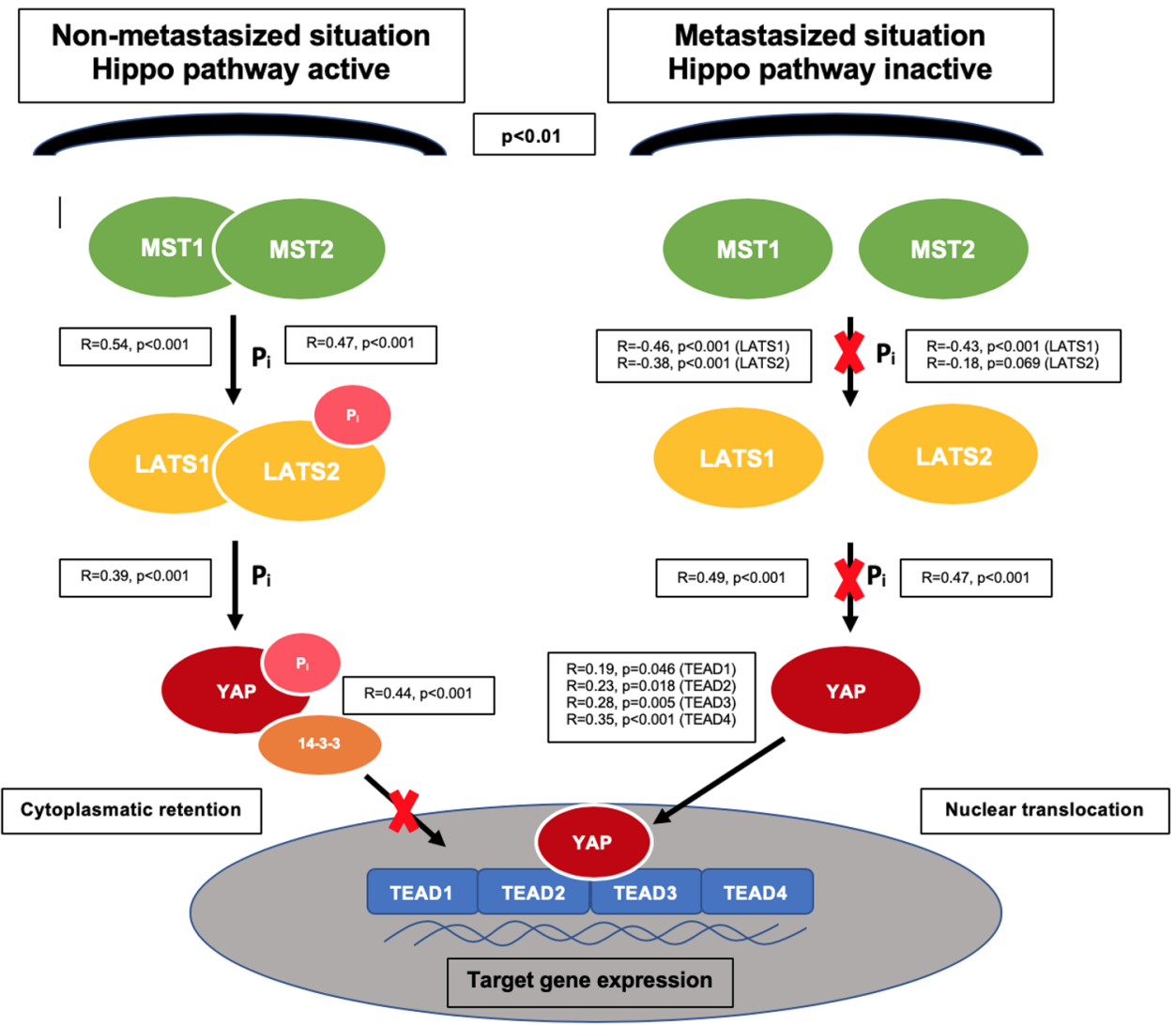

(Fig. 2). In addition, patients with a higher expression of pYAP than YAP had a significantly longer OS. Almost similar results were observed regarding the DFS, where a higher pYAP expression and a pYAP $>$ YAP ratio significantly correlated with a longer DFS (Fig. 3). These results underline the clinical importance of the Hippo pathway activity, measured by YAP and pYAP correlating to patient survival.

The effects of the Hippo pathway on proliferation, cell growth and homeostasis are mainly regulated by the nuclear transcription factors of the TEAD family including TEAD1, TEAD2, TEAD3 and TEAD4. It is widely accepted that TEAD takes plays a significant role in human cancer and the dissemination of cancer cells. However, TEAD activity and expression varies between different malignancies and has to be evaluated separately (Lamar et al. 2012; Holden and Cunningham 2018; Lin et al. 2017a, b; Huh et al. 2019). We therefore investigated the expression of each TEAD member to identify the major target of YAP after nuclear translocation in PDAC. Firstly, we found that all forms of TEAD were upregulated in PDAC compared with healthy pancreatic tissue. However, TEAD2 and TEAD3 were more frequently expressed in metastasized patients and their correlating liver metastasis, thus indicating that YAP promotes metastasis mainly through TEAD2 and TEAD3 (Fig. 4).

Focusing on prospective results, we envision huge potential in targeting the Hippo pathway to improve the prognosis of patients suffering from PDAC by preventing the metastatic spread or slowing down the rate of metastasis.

Numerous options of inhibiting the signaling pathway have been investigated as each component of the pathway could be potentially influenced. As there is evidence that crossover with other pathways exist, targeting YAP or the YAP-TEAD interaction as downstream effectors would be the preferable option (Holden and Cunningham 2018; Warren et al. 2018; Wu and Yang 2018). In addition, concentrating on YAP target genes is another promising approach as directly targeting YAP, e.g. with verteporfin. When further investigated, verteporfin was found to act as a competitor to TEAD binding site on YAP and is capable of disrupting the YAP-TEAD interaction (Liu-Chittenden et al. 2012). However, treatment with verteporfin is associated with substantial toxic side effects (Konstantinou et al. 2017; Zhang et al. 2015a, b). Nonetheless no active agents targeting YAPdriven genes promoting cancer growth, progression and metastasis have been approved for clinical use in PDAC, but it is a highly promising objective in the era of targeted therapy.

In conclusion, our study clearly shows that the Hippo pathway is inactive in metastasized patients resulting in nuclear translocation of YAP and an enhanced target gene expression via transcriptional factors TEAD2 and TEAD3 with pro-metastatic and proliferative effects. Furthermore, 
we revealed that the Hippo pathway has a huge impact on disease progression with metastatic spread and is clinically highly relevant as a shift in the balance towards the inactive pathway predicts an unfavorable OS and DFS. Therefore, we are confident that targeting the Hippo pathway could improve the outcome of patients suffering from PDAC and this role needs to be elucidated in prospective studies.

Acknowledgements This study was supported by a scientific grant from the Guenter Haenisch Foundation. The results were presented at the 51st Meeting of the European Pancreatic Club (EPC), Bergen, Norway, 26-29 June 2019. This work is part of the M.D. thesis of R. Drexler.

Author contributions RD and MKÜ for acquisition of data, analysis and interpretation of data, statistical analysis and drafting of the manuscript; TR, BF and MKL for technical and material support; KO and $\mathrm{KW}$ for study concept and design, obtainment of funding and study supervision. All authors read and approved the final manuscript.

Funding Open access funding provided by Semmelweis University. This work was supported by a scientific grant from the Guenther Haenisch Foundation.

Data availability All data generated that are relevant to the results presented in this article are included in this article. Other data that were not relevant for the results presented here are available from the corresponding author R. Drexler upon reasonable request.

\section{Compliance with ethical standards}

Conflict of interest No potential conflict of interest were disclosed by the other author.

Open Access This article is licensed under a Creative Commons Attribution 4.0 International License, which permits use, sharing, adaptation, distribution and reproduction in any medium or format, as long as you give appropriate credit to the original author(s) and the source, provide a link to the Creative Commons licence, and indicate if changes were made. The images or other third party material in this article are included in the article's Creative Commons licence, unless indicated otherwise in a credit line to the material. If material is not included in the article's Creative Commons licence and your intended use is not permitted by statutory regulation or exceeds the permitted use, you will need to obtain permission directly from the copyright holder. To view a copy of this licence, visit http://creativecommons.org/licenses/by/4.0/.

\section{References}

Boggiano JC, Vanderzalm PJ, Fehon RG (2011) Tao-1 phosphorylates Hippo/MST kinases to regulate the Hippo-Salvador-Warts tumor suppressor pathway. Dev Cell 21(5):888-895. https://doi. org/10.1016/j.devcel.2011.08.028

Chan EHY, Nousiainen M, Chalamalasetty RB, Schäfer A, Nigg EA, Silljé HHW (2005) The Ste20-like kinase Mst2 activates the human large tumor suppressor kinase Lats1. Oncogene 24(12):2076-2086. https://doi.org/10.1038/sj.onc.1208445

Chen M, Wang M, Xu S, Guo X, Jiang J (2015) Upregulation of MiR-181c contributes to chemoresistance in pancreatic cancer by inactivating the Hippo signaling pathway. Oncotarget 6(42):44466-44479. https://doi.org/10.18632/oncotarget.6298

Diep CH, Zucker KM, Hostetter G, Watanabe A, Chengcheng Hu, Munoz RM, Von Hoff DD, Han H (2012) Down-regulation of yes associated protein 1 expression reduces cell proliferation and clonogenicity of pancreatic cancer cells. PLoS ONE 7(3):e32783. https://doi.org/10.1371/journal.pone.0032783

Diepenbruck M, Waldmeier L, Ivanek R, Berninger P, Arnold P, van Nimwegen E, Christofori G (2014) Tead2 expression levels control the subcellular distribution of Yap and Taz, zyxin expression and epithelial-mesenchymal transition. J Cell Sci 127(Pt 7):15231536. https://doi.org/10.1242/jcs.139865

Ferlay J, Steliarova-Foucher E, Lortet-Tieulent J, Rosso S, Coebergh JWW, Comber H, Forman D, Bray F (2013) Cancer incidence and mortality patterns in Europe: estimates for 40 countries in 2012. Eur J Cancer 49(6):1374-1403. https://doi.org/10.1016/j. ejca.2012.12.027

Glantschnig H, Rodan GA, Reszka AA (2002) Mapping of MST1 kinase sites of phosphorylation. Activation and autophosphorylation. J Biol Chem 277(45):42987-42996. https://doi.org/10.1074/ jbc.M208538200

Gu JJ, Rouse C, Xia Xu, Wang J, Onaitis MW, Pendergast AM (2016) Inactivation of ABL kinases suppresses non-small cell lung cancer metastasis. JCI Insight 1(21):e89647. https://doi.org/10.1172/jci. insight. 89647

Han Y (2019) Analysis of the role of the Hippo pathway in cancer. J Transl Med 17(1):116. https://doi.org/10.1186/s1296 7-019-1869-4

Han S, Wang D, Tang G, Yang X, Jiao C, Yang R, Zhang Y et al (2017) Suppression of MiR-16 promotes tumor growth and metastasis through reversely regulating YAP1 in human cholangiocarcinoma. Oncotarget 8(34):56635-56650. https://doi.org/10.18632/oncot arget. 17832

Harvey KF, Zhang X, Thomas DM (2013) The Hippo pathway and human cancer. Nat Rev Cancer 13(4):246-257. https://doi. org $/ 10.1038 / \mathrm{nrc} 3458$

Hergovich A, Schmitz D, Hemmings BA (2006) The human tumour suppressor LATS1 is activated by human MOB1 at the membrane. Biochem Biophys Res Commun 345(1):50-58. https://doi. org/10.1016/j.bbrc.2006.03.244

Hogendorf P, Durczyński A, Strzelczyk J (2018) Metastatic pancreatic cancer. J Investig Surg 31(2):151-152. https://doi. org/10.1080/08941939.2017.1291774

Holden JK, Cunningham CN (2018) Targeting the Hippo pathway and cancer through the TEAD family of transcription factors. Cancers. https://doi.org/10.3390/cancers10030081

Huh H, Kim D, Jeong H-S, Park H (2019) Regulation of TEAD transcription factors in cancer biology. Cells 8(6):600. https://doi. org/10.3390/cells8060600

Ilic M, Ilic I (2016) Epidemiology of pancreatic cancer. World J Gastroenterol 22(44):9694-9705. https://doi.org/10.3748/wjg.v22. i44.9694

Kaemmerer D, Peter L, Lupp A, Schulz S, Sänger J, Baum RP, Prasad V, Hommann M (2012) Comparing of IRS and Her2 as immunohistochemical scoring schemes in gastroenteropancreatic neuroendocrine tumors. Int J Clin Exp Pathol 5(3):187-194

Kapoor A, Yao W, Ying H, Hua S, Liewen A, Wang Q, Zhong Yi et al (2014) Yap1 activation enables bypass of oncogenic Kras addiction in pancreatic cancer. Cell 158(1):185-197. https://doi. org/10.1016/j.cell.2014.06.003

Kim T, Hwang D, Lee D, Kim JH, Kim SY, Lim DS (2017) MRTF potentiates TEAD-YAP transcriptional activity causing metastasis. EMBO J 36(4):520-535. https://doi.org/10.15252/embj.20169 5137

Konstantinou EK, Notomi S, Kosmidou C, Brodowska K, Al-Moujahed A, Nicolaou F, Tsoka P et al (2017) Verteporfin-induced 
formation of protein cross-linked oligomers and high molecular weight complexes is mediated by light and leads to cell toxicity. Sci Rep 7:46581. https://doi.org/10.1038/srep46581

Lamar JM, Stern P, Liu H, Schindler JW, Jiang Z-G, Hynes RO (2012) The Hippo pathway target, YAP, promotes metastasis through its TEAD-interaction domain. Proc Natl Acad Sci USA 109(37):E2441-2450. https://doi.org/10.1073/pnas.1212021109

Lau AN, Curtis SJ, Fillmore CM, Rowbotham SP, Mohseni M, Wagner DE, Beede AM et al (2014) Tumor-propagating cells and Yap/ Taz activity contribute to lung tumor progression and metastasis. EMBO J 33(5):468-481. https://doi.org/10.1002/embj.201386082

Lei Q-Y, Zhang H, Zhao B, Zha Z-Y, Bai F, Pei X-H, Zhao S, Xiong Y, Guan K-L (2008) TAZ promotes cell proliferation and epithelial-mesenchymal transition and is inhibited by the Hippo pathway. Mol Cell Biol 28(7):2426-2436. https://doi.org/10.1128/ MCB.01874-07

Li C, Wang S, Xing Z, Lin A, Liang Ke, Song J, Qingsong Hu et al (2017) A ROR1-HER3-LncRNA signalling axis modulates the hippo-YAP pathway to regulate bone metastasis. Nat Cell Biol 19(2):106-119. https://doi.org/10.1038/ncb3464

Lin KC, Moroishi T, Meng Z, Jeong H-S, Plouffe SW, Sekido Y, Han J, Park HW, Guan K-L (2017a) Regulation of Hippo pathway transcription factor TEAD by P38 MAPK-induced cytoplasmic translocation. Nat Cell Biol 19(8):996-1002. https://doi.org/10.1038/ ncb3581

Lin KC, Park HW, Guan K-L (2017b) Regulation of the Hippo pathway transcription factor TEAD. Trends Biochem Sci 42(11):862-872. https://doi.org/10.1016/j.tibs.2017.09.003

Liu Y, Wang G, Yang Y, Mei Z, Liang Z, Cui A, Wu T, Liu C-Y, Cui L (2016) Increased TEAD4 expression and nuclear localization in colorectal cancer promote epithelial-mesenchymal transition and metastasis in a YAP-independent manner. Oncogene 35(21):2789 2800. https://doi.org/10.1038/onc.2015.342

Liu H, Suya Du, Lei T, Wang H, He X, Tong R, Wang Yi (2018a) Multifaceted regulation and functions of YAP/TAZ in tumors (review). Oncol Rep 40(1):16-28. https://doi.org/10.3892/or.2018.6423

Liu J, Ye L, Li Q, Xianqiu Wu, Wang B, Ouyang Y, Yuan Z, Li J, Lin C (2018b) Synaptopodin-2 suppresses metastasis of triple-negative breast cancer via inhibition of YAP/TAZ activity. J Pathol 244(1):71-83. https://doi.org/10.1002/path.4995

Liu-Chittenden Y, Huang B, Shim JS, Chen Q, Lee S-J, Anders RA, Liu JO, Pan D (2012) Genetic and pharmacological disruption of the TEAD-YAP complex suppresses the oncogenic activity of YAP. Genes Dev 26(12):1300-1305. https://doi.org/10.1101/ gad.192856.112

Meng Z, Moroishi T, Mottier-Pavie V, Plouffe SW, Hansen CG, Hong AW, Park HW et al (2015) MAP4K family kinases act in parallel to MST1/2 to activate LATS1/2 in the Hippo pathway. Nat Commun 6(October):8357. https://doi.org/10.1038/ncomms9357

Moroishi T, Hansen CG, Guan K-L (2015) The emerging roles of YAP and TAZ in cancer. Nat Rev Cancer 15(2):73-79. https:// doi.org/10.1038/nrc3876

Nallet-Staub F, Marsaud V, Li L, Gilbert C, Dodier S, Bataille V, Sudol M, Herlyn M, Mauviel A (2014) Pro-invasive activity of the hippo pathway effectors YAP and TAZ in cutaneous melanoma. J Investig Dermatol 134(1):123-132. https://doi.org/10.1038/ jid.2013.319

Poma AM, Torregrossa L, Bruno R, Basolo F, Fontanini G (2018) Hippo pathway affects survival of cancer patients: extensive analysis of TCGA data and review of literature. Sci Rep 8(1):10623. https://doi.org/10.1038/s41598-018-28928-3

Poon CLC, Lin JI, Zhang X, Harvey KF (2011) The sterile 20-like kinase Tao- 1 controls tissue growth by regulating the SalvadorWarts-Hippo pathway. Dev Cell 21(5):896-906. https://doi. org/10.1016/j.devcel.2011.09.012
Qiao Y, Chen J, Lim YB, Finch-Edmondson ML, Seshachalam VP, Qin L, Jiang T et al (2017) YAP regulates actin dynamics through ARHGAP29 and promotes metastasis. Cell Rep 19(8):1495-1502. https://doi.org/10.1016/j.celrep.2017.04.075

Remmele W, Stegner HE (1987) Recommendation for uniform definition of an immunoreactive score (IRS) for immunohistochemical estrogen receptor detection (ER-ICA) in breast cancer tissue. Der Pathologe 8(3): 138-140

Rozengurt E, Sinnett-Smith J, Eibl G (2018) Yes-associated protein (YAP) in pancreatic cancer: at the epicenter of a targetable signaling network associated with patient survival. Signal Transduct Target Ther 3(1):11. https://doi.org/10.1038/s41392-017-0005-2

Ryan DP, Hong TS, Bardeesy N (2014a) Pancreatic adenocarcinoma. N Engl J Med 371(22):2140-2141. https://doi.org/10.1056/NEJMc 1412266

Ryan DP, Hong TS, Bardeesy N (2014b) Pancreatic adenocarcinoma. N Engl J Med 371(11):1039-1049. https://doi.org/10.1056/NEJMr a1404198

Salcedo Allende MT, Zeron-Medina J, Hernandez J, Macarulla T, Balsells J, Merino X, Allende H, Tabernero J, Agüeras SRYC (2017) Overexpression of yes associated protein 1, an independent prognostic marker in patients with pancreatic ductal adenocarcinoma, correlated with liver metastasis and poor prognosis. Pancreas 46(7):913-920. https://doi.org/10.1097/MPA.0000000000000867

Saucedo LJ, Edgar BA (2007) Filling out the Hippo pathway. Nat Rev Mol Cell Biol 8(8):613-621. https://doi.org/10.1038/nrm2221

Siegel RL, Miller KD, Jemal A (2018) Cancer statistics, 2018. CA Cancer J Clin 68(1):7-30. https://doi.org/10.3322/caac.21442

van Rensburg HJJ, Yang X (2016) The roles of the Hippo pathway in cancer metastasis. Cell Signal 28(11):1761-1772. https://doi. org/10.1016/j.cellsig.2016.08.004

Vincent A, Herman J, Schulick R, Hruban RH, Goggins M (2011) Pancreatic cancer. Lancet 378(9791):607-620. https://doi. org/10.1016/S0140-6736(10)62307-0

Wang T, Mao B, Cheng C, Zou Z, Gao J, Yang Y, Lei T et al (2018) YAP promotes breast cancer metastasis by repressing growth differentiation factor-15. Biochim Biophys Acta Mol Basis Dis 1864(5 Pt A):1744-1753. https://doi.org/10.1016/j.bbadi s.2018.02.020

Warren J, Xiao Y, Lamar J (2018) YAP/TAZ activation as a target for treating metastatic cancer. Cancers 10(4):115. https://doi. org/10.3390/cancers10040115

Wei H, Zongzhen Xu, Liu F, Wang F, Wang X, Sun X, Li J (2017) Hypoxia induces oncogene yes-associated protein 1 nuclear translocation to promote pancreatic ductal adenocarcinoma invasion via epithelial-mesenchymal transition. Tumour Biol 39(5):1010428317691684. https://doi.org/10.1177/1010428317 691684

Wu L, Yang X (2018) Targeting the Hippo pathway for breast cancer therapy. Cancers 10(11):422. https://doi.org/10.3390/cancers 101 10422

Wu J, Liu T, Rios Z, Mei Q, Lin X, Cao S (2017) Heat shock proteins and cancer. Trends Pharmacol Sci 38(3):226-256. https://doi. org/10.1016/j.tips.2016.11.009

Xie D, Cui J, Xia T, Jia Z, Wang L, Wei W, Zhu A, Gao Y, Xie K, Quan M (2015) Hippo transducer TAZ promotes epithelial mesenchymal transition and supports pancreatic cancer progression. Oncotarget 6(34):35949-35963. https://doi.org/10.18632/oncot arget.5772

Yang S, Zhang L, Purohit V, Shukla SK, Chen X, Yu F, Fu K et al (2015) Active YAP promotes pancreatic cancer cell motility, invasion and tumorigenesis in a mitotic phosphorylation-dependent manner through LPAR3. Oncotarget 6(34):36019-36031. https ://doi.org/10.18632/oncotarget.5935 
Yu F-X, Zhao B, Guan K-L (2015) Hippo pathway in organ size control, tissue homeostasis, and cancer. Cell 163(4):811-828. https ://doi.org/10.1016/j.cell.2015.10.044

Yuan Y, Li D, Li H, Wang L, Tian G, Dong Y (2016) YAP overexpression promotes the epithelial-mesenchymal transition and chemoresistance in pancreatic cancer cells. Mol Med Rep 13(1):237-242. https://doi.org/10.3892/mmr.2015.4550

Zanconato F, Cordenonsi M, Piccolo S (2016) YAP/TAZ at the roots of cancer. Cancer Cell 29(6):783-803. https://doi.org/10.1016/j. ccell.2016.05.005

Zhang W, Nandakumar N, Shi Y, Manzano M, Smith A, Graham G, Gupta $S$ et al (2014) Downstream of mutant KRAS, the transcription regulator YAP is essential for neoplastic progression to pancreatic ductal adenocarcinoma. Sci Signal 7(324):ra42. https ://doi.org/10.1126/scisignal.2005049

Zhang H, Ramakrishnan SK, Triner D, Centofanti B, Maitra D, Győrffy B, Sebolt-Leopold JS et al (2015a) Tumor-selective proteotoxicity of verteporfin inhibits colon cancer progression independently of YAP1. Sci Signal 8(397):ra98. https://doi.org/10.1126/scisignal. aac5418

Zhang K, Qi H-X, Zhi-Mei Hu, Chang Y-N, Shi Z-M, Han X-H, Han Y-W et al (2015b) YAP and TAZ take center stage in cancer.
Biochemistry 54(43):6555-6566. https://doi.org/10.1021/acs. biochem.5b01014

Zhao B, Wei X, Li W, Udan RS, Yang Q, Kim J, Xie J et al (2007) Inactivation of YAP oncoprotein by the hippo pathway is involved in cell contact inhibition and tissue growth control. Genes Dev 21(21):2747-2761. https://doi.org/10.1101/gad.1602907

Zhou Z, Zhu J-S, Gao C-P, Li L-P, Zhou C, Wang H, Liu X-G (2016) SiRNA targeting YAP gene inhibits gastric carcinoma growth and tumor metastasis in SCID mice. Oncol Lett 11(4):2806-2814. https://doi.org/10.3892/ol.2016.4319

Zhou Q, Bauden M, Andersson R, Dingyuan Hu, Marko-Varga G, Jianfeng Xu, Sasor A et al (2020) YAP1 is an independent prognostic marker in pancreatic cancer and associated with extracellular matrix remodeling. J Transl Med 18(1):77. https://doi. org/10.1186/s12967-020-02254-7

Zygulska AL, Krzemieniecki K, Pierzchalski P (2017) Hippo pathway - brief overview of its relevance in cancer. J Physiol Pharmacol 68(3):311-335

Publisher's Note Springer Nature remains neutral with regard to jurisdictional claims in published maps and institutional affiliations. 